\title{
INDUSTRIAS AERONÁUTICAS Y MECÁNICAS DEL ESTADO Y LA LÓGICA DE LA POLÍTICA ECONÓMICA PERONISTA
}

\author{
STATE AERONAUTICAL AND MECHANICAL \\ INDUSTRIES AND THE LOGIC OF THE PERONIST \\ ECONOMIC POLICY
}

\author{
Mario Raccanello \\ Universidad de Buenos Aires, Argentina, <marioraccanello@yahoo.com.ar>
}

\begin{abstract}
Resumen. En este artículo se exhibe el desarrollo productivo de Industrias Aeronáuticas y Mecánicas del Estado (IAME), un conglomerado metalmecánico creado en el marco del Segundo Plan Quinquenal del gobierno de Juan Domingo Perón, y se analiza la lógica económica del movimiento peronista en su fase clásica. A la luz de diversas contribuciones teóricas y empíricas, se discuten temáticas conjugadas por el objeto de estudio, tales como el grado de desarrollo industrial alcanzado, la incorporación tecnológica, la postura frente al capital extranjero y la densidad económica de la estrategia de industrialización peronista.
\end{abstract}

Palabras clave: peronismo, industria automotriz, industria aeronáutica.

\begin{abstract}
This paper shows the productive development of Industrias Aeronáuticas y Mecánicas del Estado (IAME), a metal-mechanic conglomerate created within the framework of the Second Five-Year Plan of Juan Domingo Peron's government, and analyzes the economic logic of the Peronist movement in its classical phase. In light of various theoretical and empirical contributions, issues conjugated by the object of study will be discussed, such as the degree of industrial development reached, the incorporation of technology, the attitude towards foreign capital and the economic density of the Peronist industrialization strategy.
\end{abstract}

Key words: peronism, automobile industry, aircraft industry.

Fecha de recepción: septiembre de 2011. Fecha de aceptación: julio de 2012.

Am. Lat. Hist. Econ., año 20, núm. 2, mayo-agosto, 2013, pp. 177-221 


\section{INTRODUCCIÓN}

$\mathrm{E}$ 1 siguiente artículo se propone analizar e interpretar la experiencia industrial -y experimental- de Industrias Aeronáuticas y Mecánicas del Estado (en adelante IAME) en la lógica de la política económica del peronismo clásico.

Para la trayectoria evolutiva recorrida por la primigenia Fábrica Militar de Aviones, fue en los años en que el peronismo la reconvirtió en IAME cuando se produjeron las mayores transformaciones en la dinámica productiva de la empresa estatal. Para la investigación en historia económica, examinar a IAME se vuelve un ejercicio sumamente enriquecedor porque permite contemplar y discutir la lógica política-económica del peronismo tradicional, oculta detrás del manejo de la cuestión industrial.

Autores previos han recalado en el caso de IAME, presentando motivaciones diferentes para abordar su estudio: la exploración de la primera fase de la industria automotriz; la exposición de los logros de la producción e investigación aeronáutica; la definición del móvil del capitalismo estatal; la distinción de las cualidades de los ingenieros militares; el desarrollo de economías regionales, o bien, la conformación de redes técnicas de producción industrial.

El presente artículo aborda cuestiones como las anteriores pero buscará conjugarlas y consolidarlas para construir una "metáfora explicativa" que permita cumplir con el propósito de discutir la naturaleza económica del movimiento político dirigido por Juan Domingo Perón. En particular, IAME, como producto socioeconómico, presenta una infinidad de cualidades que llevan el sello indeleble de la acción económica del peronismo. En este sentido, a partir de este estudio de caso, el artículo se propone delinear una economía del comportamiento peronista. Interrogantes que se hiciera Schvarzer sobre la política económica de la última dictadura militar argentina,${ }^{2}$ los trasladaremos para dilucidar aquella que fue pergeñada por el peronismo: cंoperaron "meta-políticas económicas" -en la terminología de Schvarzer, transformaciones estructurales derivadas de medidas aparentemente coyunturales-?, ¿qué relación se manifiesta entre el discurso de las autoridades -especialmente el del mismo Perón $-^{3}$ y la consistencia

${ }^{1}$ Katz, Ford, 2009, p. 35.

${ }^{2}$ Schvarzer, Martínez, 1983.

${ }^{3}$ Por este motivo, en este artículo se exponen diversas alocuciones de Perón. No obstante, "[n]o es sensato centralizar la reflexión acerca del peronismo en los discursos de Perón... Un discurso de Perón es un discurso de Perón... No hay discurso de Perón que no encuentre en algún otro su contracara", Feinmann, Peronismo, 2010, p. 121. Lo relevante de los discursos no es encontrar la concordancia o contradicción entre ellos, sino la concordancia o contradicción entre los hechos económicos a los que se refieren. 
de la política económica?, ¿las políticas económicas disciplinaron a los actores sociales?

Para desarrollar este artículo, me he valido de la utilización de fuentes primarias como el Libro histórico, 1926-1976, del Área de Material Córdoba; la Reseña histórica de la Dirección Nacional de Fabricaciones e Investigaciones Aeronáuticas en su 40 aniversario de 1968; las Actas de Directorio de IAME, de abril de 1956 a febrero de 1957, ${ }^{4}$ y las Memorias y balances generales de la Dirección Nacional de Fabricaciones e Investigaciones Aeronáuticas (DINFIA) correspondientes a los ejercicios económicos de 1957, 1960-1961, 1962-1963 y 1965. He procedido a la búsqueda de fuentes directas internas de IAME durante el peronismo (1952-1955) en los principales reservorios de documentación aeronáutica como la Biblioteca Nacional de Aeronáutica o la Dirección de Estudios Históricos de la Fuerza Aérea Argentina, así como también en el Departamento del Archivo Intermedio del Archivo General de la Nación, el cual alberga los fondos documentales de los organismos del Estado. Como ha sucedido a investigadores anteriores, no he podido encontrar la documentación oficial de la Fábrica Militar de Aviones referida en el periodo en cuestión, ${ }^{5}$ quedando como sustituto imperfecto pero como publicación oficial de este periodo la Revista Nacional de Aeronáutica, con su detallada descripción de las novedades en torno a cada una de las actividades de Industrias Aeronáuticas y Mecánicas del Estado.

$\mathrm{El}$ artículo se estructura del siguiente modo. La primera sección consiste en un estado de la cuestión integrado por las tesis de trabajos que, desde distintos ángulos y distancias al objeto de investigación, aportan a su problematización como al rastreo de muchas de sus claves interpretativas. La segunda describe las condiciones económicas de Argentina que fueron antesala al nacimiento de IAME. La tercera sección recorre las múltiples aristas de la experiencia tecnoproductiva de IAME entre 1952 y 1955. La siguiente sección ingresa en el análisis de las relaciones que el peronismo comienza a establecer con el capital extranjero a través de IAME; posteriormente, se exhiben los resultados obtenidos por el peronismo en el desarrollo del sector metalmecánico. Finalmente, se presenta un balance de la experiencia IAME, una serie de reflexiones sobre la lógica de la política económica peronista desprendidas de las evidencias obtenidas con

${ }^{4}$ Industrias, Actas, núms. 13-52.

${ }^{5} \mathrm{Al}$ consultarse sobre los motivos de la ausencia de documentación oficial particular para los años de IAME a coordinadores de la Dirección de Estudios Históricos de la Fuerza Aérea Argentina (investigadores y custodios de los fondos documentales en los que se asienta el acervo histórico aeronáutico argentino), barajaron las siguientes explicaciones: pérdida por traslado del material, robo, desidia de la Fuerza Área para conservar documentación, eliminación involuntaria y, por último, la factible destrucción consciente por parte de la o las dictaduras que sobrevendrían al fin del peronismo clásico. 
el estudio de caso y el debate de algunas de las tesis desarrolladas hasta el momento en relación con los temas aquí tratados.

\section{DEBATES EN TORNO AL ESTADO: DESARROLLISTA, EMPRESARIO Y PERONISTA}

Para interpelar y dimensionar el comportamiento productivo de IAME, será necesario discurrir con antelación sobre los campos temáticos conjugados por nuestro objeto de análisis, como también presentar las tesis de investigaciones previas que han enfocado en distintos ejes sobre los que ha girado el comportamiento de la empresa estatal estudiada. Por consiguiente, primero se ahondará en la literatura en torno al Estado desarrollista, para luego referirse a la aún incipiente historiografía del Estado empresario. También, se presentarán las interpretaciones efectuadas por investigadores que han puesto bajo su lupa el desarrollo industrial argentino durante el peronismo clásico (1946-1955), sentándose luego una reseña de los estudios previos que han tratado el caso IAME.

\section{Pensando el Estado desarrollista}

En su obra de 1949 Raúl Prebisch, padre del estructuralismo latinoamericano -y a la vez crítico de la concepción económica autarquizante del peronismo-, advirtió el deterioro sostenido en la relación de precios entre los bienes producidos por los países periféricos y desarrollados. Para Prebisch, la complejización de las estructuras productivas era la única alternativa que podía contraponerse ante el proceso de transferencia internacional de la riqueza que se implicaba bajo su tesis. ${ }^{6}$ En el esfuerzo por "desarroll[arse] desde dentro", el Estado debía convertirse en el programador de la industrialización sustitutiva. Sin embargo, no debía descuidarse la sagacidad de la intervención económica; en este sentido los regímenes de promoción industrial deberían ser selectivos, frutos de una planificación concienzuda, dinamizadores de la inversión y la sofisticación tecnológica y ajenos a tomar ribetes estatistas que ahogaran la iniciativa privada.

Ferrer señalaba que

el desarrollo de las economías atrasadas exige un intenso esfuerzo colectivo de estímulo y organización de las capacidades productivas, que dada la debilidad de la empresa privada, sólo puede ser puesto en marcha por el Estado. Por otra parte, y aunque parezca paradójico, el fortalecimiento de la empresa privada y su

${ }^{6}$ Prebisch, "Desarrollo", 1949. 
aporte efectivo al progreso económico y social depende de que el Estado cree las condiciones básicas que lo permitan. ${ }^{7}$

En otros términos, sea por impotencia (por carecer de capacidades productivas, tecnológicas o financieras) o desinterés (una rentabilidad esperada demasiado baja en un ambiente riesgoso) del capital privado, ante la presencia de tales fallas de mercado el Estado debe asumirse como el "motor" del desarrollo económico.

Rosenstein-Rodan había marcado también la conveniencia de la industrialización promovida por el Estado, principalmente a razón de las ingentes necesidades de capital requeridas para desarrollar determinadas actividades manufactureras: de allí la urgencia por un big push. ${ }^{8}$ Gerschenkron retoma esta cuestión resaltando la función del Estado como movilizador del capital hacia actividades de una envergadura que no podrían ser encaradas por los actores privados locales. Las acciones de promoción desde la banca de desarrollo o a través de la actividad empresarial misma irían en tal dirección. ${ }^{9}$

Albert Hirschman también exaltó la intervención estatal, sugiriendo la introducción de desequilibrios en la estructura productiva. Más que en la insuficiencia de capital, Hirschman carga las tintas en la ausencia de capacidad empresarial para asumir los riesgos que implica el desarrollo de las industrias dinámicas. En consecuencia, el Estado debe inducir incentivos en el empresariado privado a través de su acción desequilibrante, cercenando los cuellos de botella que contienen la disposición a invertir. Para ello, Hirschman exalta la generación de eslabonamientos hacia atrás y adelante que estimulen un desarrollo productivo integrado. Para tal fin, la conversión del Estado en agente empresario es considerada por Hirschman una iniciativa pertinente. ${ }^{10}$

Schumpeter estimó el papel del Estado como inductor del cambio tecnológico. El Estado "innovador" crearía incentivos que propendieran a un proceso de innovación privada continua, a través de acciones como el apoyo a sectores estratégicos para el desarrollo, impulso a la $\mathrm{I}+\mathrm{D}$, acceso a nuevas tecnologías y difusión del conocimiento. Schumpeter no rechazaba la intervención directa del Estado en la producción, siempre y cuando esta sea eficiente y continuara operando en una economía de mercado libre. ${ }^{11}$

Según Boudeville, un polo de crecimiento se genera cuando en una región rezagada se instala una gran unidad (empresarial) motriz que, por

\footnotetext{
${ }^{7}$ Ferrer, Estado, 1956, pp. 8-9.

${ }^{8}$ Rosenstein-Rodan, "Problems", 1943.

${ }^{9}$ Gerschenkron, Economic, 1962.

${ }^{10}$ Véase Hirschman, Strategy, 1958.

${ }^{11}$ Véase Schumpeter, Capitalismo, 1946.
} 
su demanda pujante de factores productivos, genera efectos benéficos en el ámbito local (aumento de la demanda, instalación de proveedores, crecimiento de la inversión, reinversión de excedentes, desarrollo de infraestructura y capital social, imitación y aprendizaje). ${ }^{12}$ Esta concepción de Boudeville se conecta con la causación circular acumulativa de Myrdal, donde a partir de la introducción de economías de escala y alcance como externalidades tecnológicas, se da paso a una imbricación continua y creciente de la innovación, las capacidades dinámicas y el mercado interno. ${ }^{13}$

Por último, en 1996 Peter Evans introduce el concepto de "autonomía enraizada", entendiéndola como la reciprocidad que se establece entre una burocracia estatal de carácter weberiano y una estructura empresaria promocionada pero ceñida a los lineamientos y condiciones trazados originariamente por la planificación económica. Evans señala a la autonomía enraizada como el factor clave de los Estados desarrollistas, es decir, de la eficacia de la acción estatal en la consecución del desarrollo económico. ${ }^{14}$

\section{En las tierras del Estado empresario}

Por Estado empresario entenderemos al "Estado con capacidades para impulsar o sostener no sólo las actividades empresariales propias, sino también otras de naturaleza privada y en las que participa directamente de manera relativa o sólo lo hace inicialmente" ${ }^{15}$ Este Estado empresario se constituyó en un actor principal del desarrollo de las capacidades locales de las actividades básicas de la industria argentina y latinoamericana en la posguerra. ${ }^{16}$

Entre los primeros autores que indagaron en la formación de las empresas estatales argentinas, Schvarzer se ha destacado al introducir el concepto de "complejo estatal-privado", con el que apuntaba a las tramas productivas desplegadas por las organizaciones empresarias del Estado al entablar relaciones económicas con el sector privado. Para este autor, allí residía no sólo la clave del desarrollo industrial -sobre todo de las ramas dinámicas-, sino la condición de existencia de la estructura productiva, debida más al impulso estatal que a la iniciativa privada. ${ }^{17}$ Recientemente, Castellani y Odisio han redimensionado el concepto de Schvarzer; la primera, refiriéndose a la creación de ámbitos estratégicos de acumulación o

\footnotetext{
12 Boudeville, Problems, 1966.

${ }^{13}$ Véase Myrdal, Economic, 1957.

14 Evans, Estado, 1996.

${ }^{15}$ Rougier, “¿Elefante?”, 2009, p. 224.

${ }^{16}$ Véase Belini y Rougier, Estado, 2008.

${ }^{17}$ Schvarzer, "Empresas", 1979.
} 
ámbitos privilegiados de acumulación (respectivamente, proclives y contrarios al desarrollo) para las empresas privadas ligadas al funcionamiento del complejo, y el segundo, distinguiendo las relaciones verticales (desde la política económica al funcionamiento de los mercados) y horizontales (con empresas eslabonadas hacia atrás y adelante) entabladas por la empresa pública (nodo central del complejo). ${ }^{18}$

Schvarzer se había inspirado en realidad en el "nuevo Estado industrial" de Galbraith, específicamente en la figura del complejo militar-industrial estadunidense. Siguiendo a Rougier, la función militar de la defensa ha estado históricamente detrás de la creación de empresas públicas y del papel del Estado tanto como productor y demandante de bienes (respectivamente, mecanismos directos e indirectos). ${ }^{19}$ Para el autor, el complejo militar industrial de posguerra es el núcleo duro del complejo estatal-privado.

\section{Interpretaciones sobre el peronismo industrial}

Originariamente como figuración enarbolada por el propio movimiento político, la asociación entre peronismo e industria se ha convertido en foco de debate al interior de las ciencias sociales.

Predominantemente la literatura le ha atribuido al peronismo clásico haber elegido a la industria como la fuerza motriz de la actividad económica, el eje ordenador de las relaciones socioeconómicas y el cuerpo integrador de los sectores postergados. En este sentido, el régimen peronista ha sido considerado como el primer gobierno argentino con una "posición firmemente industrialista" ${ }^{20}$ La irrupción del peronismo ha sido presentada entonces como una divisoria de aguas, donde se pone término al agónico modelo oligárquico agroexportador para forjar una industrialización dirigida por el Estado que alumbra a la burguesía nacional y a un proletariado alzado en sus derechos. ${ }^{21}$

El peronismo también es visto por otros como punto de inflexión, pero en un sentido opuesto al anterior. Desde el liberalismo económico, le asignan al peronismo haber dado origen al retroceso económico de Argentina, alejando al país del patrón de crecimiento internacional vía el establecimiento de un esquema autárquico para su economía. Incluso, Díaz Alejandro le niega al peronismo ser un gobierno verdaderamente industrialista, pues en su objetivo nacional y popular, bregó por el aumento

\footnotetext{
${ }^{18}$ Véanse Castellani, “Ámbitos”, 2011, y Odisio, “Capacidades”, 2011.

${ }^{19}$ Rougier, "Militares", 2011.

${ }^{20}$ Rapoport, Historia, 2000, p. 426.

${ }^{21}$ Véase Basualdo, "Primeros", 2005.
} 
del consumo real, la ocupación y la seguridad económica de las masas y los empresarios, sacrificando las oportunidades que brindaba la economía de posguerra para la formación de capital y la transformación de la matriz productiva (incorporación de los sectores básicos, búsqueda de una mayor eficiencia, etc.). ${ }^{22}$

Desde el marxismo, Milcíades Peña efectuó un análisis pormenorizado de la industrialización cobijada por el peronismo. Para Peña, con el peronismo se profundizaron las deficiencias estructurales del proceso de seudoindustrialización argentina: baja composición técnica del capital (el crecimiento industrial descansa fundamentalmente sobre la incorporación de mano de obra y el agotamiento de las instalaciones disponibles), crecimiento excesivo de la producción de bienes de consumo versus insuficiente desarrollo de las industrias básicas y las fuentes de energía, baja productividad del trabajo y costos de producción elevados, predominio de la pequeña industria antieconómica. ${ }^{23}$ Muchos años después a los escritos de Peña, su colaborador Jorge Schvarzer daría evidencias de la ausencia de prioridades definidas y estímulos significativos para el desarrollo industrial durante el peronismo. ${ }^{24}$

Basualdo, interpretando al peronismo como ruptura en lo social, político y económico ${ }^{25}$, indicará que la integración de la estructura productiva mediante la incorporación de la rama pesada -su deuda con la industria-, no fue posible, no por la política de redistribución del ingreso o la nacionalización de los servicios públicos -como se asevera desde la ortodoxia-, sino por las ganancias extraordinarias percibidas por la burguesía industrial (mayores para el capital extranjero). Para este autor, si tales recursos se hubieran canalizado hacia el Estado empresario -el peronismo no logró una estatización suficiente para impulsar el desarrollo-, se podría haber instalado la industria pesada y así consolidado la industrialización.

En el trabajo de mayor especificidad escrito sobre la cuestión, Belini afirma que el peronismo no tuvo una política industrial, entendiéndola como "un conjunto ordenado de instrumentos destinados a estimular el crecimiento de ciertas industrias seleccionadas en el marco de una política de desarrollo" ${ }^{26}$ No obstante, para el autor la política peronista potenció el cambio en la orientación de las políticas públicas hacia el sector industrial que se había dado con el gobierno militar que lo antecedió. En referencia

\footnotetext{
${ }^{22}$ Díaz, Ensayos, 1975, p. 129.

${ }^{23}$ Peña, Industrialización, 1986.

${ }^{24}$ Schvarzer, Industria, 2000.

${ }^{25}$ Para Basualdo el peronismo quiebra la hegemonía del agro sobre la industria. Basualdo, "Primeros", 2005.

${ }^{26}$ Belini, Industria, 2009.
} 
al Segundo Plan Quinquenal, ${ }^{27}$ Belini lo considera un reconocimiento por parte del peronismo de la escasa integración de la estructura industrial; sin embargo, pese a haber introducido una jerarquía de prioridades para con las ramas básicas, la escasez de divisas horadó su instrumentación. Asimismo, para Belini, al fracaso del Estado industrial del peronismo colaboraron la falta de bienes de capital e insumos, la ausencia de una orientación estratégica (al menos hasta 1952) y la falta de capacidades burocráticas y técnicas.

Rougier sostiene que entre 1946 y 1955 no hubo una directriz industrial específica y uniforme que fuera el eje de la política económica. La política industrial tampoco puede considerarse autónoma, pues la suerte de la industria, en su necesidad de divisas y sin poder generarlas por sí misma, termina dependiendo del sector agrario y la inversión extranjera. Por último, Rougier le niega al peronismo histórico la existencia de una estrategia orgánica de desarrollo de largo plazo para la actividad industrial. De lo anterior, surge para Rougier que la asociación entre peronismo e industria, o peronismo y estatismo, no fue convalidada por la realidad. ${ }^{28}$

\section{Aproximaciones historiográficas al caso IAME}

Desde la historiografía académica, una serie de autores ha recalado en IAME, a veces para abordar cuestiones concretas a su extensa dinámica productiva, otras como insumo empírico para colaborar a un objeto de investigación de mayor agregación.

En la tradición marxista, Ansaldi expuso a IAME como el vaso conductor de la acción del Estado peronista que terminó transformando la protoindustria de la capital mediterránea en gran industria dependiente del capital extranjero. ${ }^{29}$ Angueira y Tonini abordaron el funcionamiento del capitalismo de Estado en Argentina a partir del caso de la Fábrica Militar de Aviones entre 1927 y 1956, planteando como hipótesis que "mientras más se desarrolla el capitalismo de Estado y mayor es su injerencia en la economía de un país dependiente, mayor es su dependencia del capital extranjero". ${ }^{30}$ En línea con la interpretación desarrollada por Ansaldi, Angueira y Tonini consideran que la venida auxiliadora del capital extranjero al conglomerado metalmecánico cordobés actúa como representación del

\footnotetext{
${ }^{27}$ Presidencia, Segundo, 1953.

${ }^{28}$ Rougier, Economía, 2012.

${ }^{29}$ Ansaldi, "Córdoba", 1979.

${ }^{30}$ Angueira y Tonini, Capitalismo, 1986, p. 11.
} 
rápido agotamiento del modelo de desarrollo industrial de corte nacional de la segunda sustitución de importaciones. En diferencia con esta visión marxista, desde el pensamiento nacional y popular, Chávez representa la historia de IAME como la "mejor tradición industrialista independiente del país". ${ }^{31}$

Aunque por fuera de la academia, Frenkel desarrolló un notable trabajo de investigación para reconstruir la vida del conductor de IAME, el brigadier Juan Ignacio San Martín. Esta obra excede sus fines biográficos, pues ahonda en el desarrollo aeronáutico argentino como condición sine qua non de la producción automotriz local y la industrialización cordobesa. ${ }^{32}$

Belini analizó la dinámica evolutiva de la industria automotriz entre 1943 y 1958. Para el autor, el gobierno peronista no elaboró una compleja política sectorial, aunque asumió el objetivo de desarrollar la rama tomando el papel de regulador y de productor. Una de las tres experiencias clave de la política sectorial de esos años que analiza Belini es justamente la que concierne a IAME, el Estado como empresario industrial. Bajo la experiencia de IAME, Belini señala que la política sectorial no fue lo suficientemente consistente y racional para integrar con éxito la cadena de valor (por los límites que imponía la escasamente desarrollada industria auxiliar) o alcanzar economías de escala y especialización que permitieran condiciones mínimas de eficiencia de la producción. ${ }^{33}$ Por su parte, Harari asume que tales resultados no responden en sí a una política sectorial inadecuada, sino a la imposibilidad sistémica de que una economía capitalista periférica pueda alcanzar de forma autónoma una producción a escala en una industria dinámica como la automotriz. ${ }^{34}$

Desde la sociología de la tecnología, Picabea analiza la producción mecánica de Industrias Mecánicas del Estado en el marco del ascenso y caída del "tecnonacionalismo". ${ }^{35}$ Para Picabea, el gobierno peronista demostró ser un férreo defensor del proyecto tecnonacionalista, hecho que sería demostrado por la estrategia "nacionalista tecnológica" consistente en el despliegue de la producción de artefactos mecánicos (los cuales a su vez, eran corporización física de la ideología peronista) por parte de IA$\mathrm{ME} .{ }^{36} \mathrm{El}$ régimen de facto posterior, en cambio, con su propuesta privatista buscó desarticular la estrategia tecnonacionalista como la alianza sociotéc-

${ }^{31}$ Chávez, "IME", 1980, p. 28.

${ }^{32}$ Frenkel, Juan, 1992.

${ }^{33}$ Belini, "Negocios", 2006.

${ }^{34}$ Harari, "Crónica", 2007.

${ }^{35}$ Concepto desarrollado por Thomas para definir al desarrollo tecnológico e industrial que, planificado, controlado y hasta profesado por el Estado, promueve la autonomía económica y la autodeterminación política por medio de la integración y endogeneización de capacidades tecnológicas y productivas (capabilities), Thomas, "Dinâmicas", 1999.

${ }^{36}$ Picabea, "Apogeo", 2011, p. 15. 
nica ${ }^{37}$ coordinada por el peronismo. En contraste con la centralidad del capital extranjero bajo el desarrollismo del gobierno frondizista (1958-1962) -al cual considera un caso especial de tecnonacionalismo-, para Picabea la centralidad de la alianza sociotécnica metalmecánica durante el peronismo residió en IAME, siendo su tecnonacionalismo impulsado de modo endógeno al basarse en el capital estatal y el privado nacional.

También desde la sociología de la tecnología, Artopoulos exploró el proyecto aeronáutico Pulqui II de la Fábrica Militar de Aviones. El autor señala que tal experiencia resultó en un "fracaso exitoso": en el marco del cambio del paradigma tecnológico -fruto del "cambio de rumbo" económico-, se renunció a la innovación radical de la industria militar para la defensa para retroceder a la innovación incremental en nuevas industrias civiles dedicadas al aprovisionamiento del mercado interno. Así, el Pulqui II habría funcionado de bisagra en la historia tecnológica argentina y de disparador de la segunda fase de la industrialización sustitutiva; en palabras del autor, "tuvo que morir el Pulqui II para que naciera el [automóvil de Industrias Kaiser Argentina] Torino". ${ }^{38}$

\section{ARGENTINA YA NO ERA UNA FIESTA: EL GENERAL ANDA CORTO DE DIVISAS}

A inicios de la segunda posguerra, el proceso de industrialización argentino continuaba gravitando sobre la importación de maquinarias e insumos básicos, siendo manifiesta la escasa integración de la actividad manufacturera. En los centros urbanos, la prosperidad económica motorizó una creciente demanda de automóviles acorde a suplir el exiguo parque automotor, sólo posible de ser cubierta por medio del flujo externo. Mientras tanto, en las explotaciones rurales, la descapitalización despuntada primero con la crisis del treinta y luego agudizada por el conflicto bélico internacional, exigía una masiva incorporación de máquinas agrícolas, especialmente de cosechadoras y tractores: fabricación local incipiente de las primeras, inexistente de los segundos.

Con la crisis de divisas de finales de los años cuarenta, el peronismo pasó a enfrentar la primera depresión de la economía argentina de natu-

${ }^{37}$ Por alianza sociotécnica -otro concepto de Thomas-, se entiende a la red de relaciones establecidas entre actores (organismos públicos, empresas privadas, usuarios) y artefactos a lo largo de una trayectoria sociotécnica, en donde elementos heterogéneos operan de intermediarios (conocimientos, capacidades, capital, infraestructura, insumos, bienes finales). Thomas, "Dinâmicas", 1999.

${ }^{38}$ Véanse Artopoulos, Tecnología, 2012, p. 71, y Rougier, Economía, 2012. 
raleza cíclica stop and go. ${ }^{39}$ En 1949, con la reversión de los términos de intercambio (-11\%), la economía peronista tuvo su primer año de contracción. En los siguientes dos se retomó el crecimiento, aunque a tasas bastante menores a las de los primeros años dorados. Para 1951 la economía argentina discurría por una nueva fase ascendente del ciclo, manifiesta por un crecimiento de las importaciones muy por encima de aquel exhibido por las ventas externas (63\% contra menos de $20 \%$ ), resultando en la conversión del superávit de 122000000 de dólares de 1950 en un déficit de 311 para 1951. En 1952, al combinarse condiciones climáticas y términos de intercambio más graves que en 1949, la situación económica se volvió sombría. Pese al establecimiento de restricciones sobre las importaciones, el déficit comercial de 1952 se terminó incrementando 60\% (véase gráfica 1).

Ante la dependencia comercial, cuando el frente externo crujía -por la lógica de crecimiento de las economías stop and go, sometidas a bruscos descensos de los términos de intercambio- la carestía de divisas no permitía dar continuidad a la expansión industrial, ni capitalizar al sector que las generaba y mucho menos satisfacer una demanda pronunciada de bienes de consumo durable como la automotriz.

A través del Segundo Plan Quinquenal (1953-1955), el peronismo se propuso atacar el desequilibrio externo promoviendo el desarrollo de actividades industriales básicas y pesadas -no obstante, el impulso a la producción agropecuaria, vigente desde 1949, fue la meta económica que adquirió mayor prioridad entre aquellas perseguidas bajo la nueva planificación. El Segundo Plan Quinquenal le asignó al Estado, sea a través de su participación directa o auspiciando al sector privado, la promoción del establecimiento y consolidación de actividades industriales estratégicas para lograr la "autarquía de la economía social y la defensa del país",

${ }^{39}$ Desde fines de la segunda guerra mundial hasta mediados de la década de 1960, la economía argentina de la sustitución de importaciones estuvo sometida a una dinámica cíclica de expansión y crisis derivada de los saldos resultantes de la balanza de pagos (específicamente de la balanza comercial, en un escenario de oferta de crédito prácticamente inexistente). En la fase ascendente del ciclo -denominado ciclo de stop and go-, la demanda creciente de los sectores populares -aumento de los salarios reales mediante- hacía mella en el nivel de los saldos exportables, mientras que la expansión industrial aceleraba la importación de bienes de capital e insumos intermedios. Ante una oferta agropecuaria estancada y la ausencia de otro sector económico capaz de acumular divisas, surgía la "restricción externa", la cual era, sin modificaciones de la estructura productiva que deshabilitaran su generación, únicamente superada trastocando la paridad cambiaria y aplicando políticas fiscales y monetarias contractivas. A través de la transferencia de ingresos al sector rural y la depresión del mercado interno industrial, se contraían las importaciones y aumentaban (ligeramente) las ventas externas, recuperándose cruentamente entonces el equilibrio de la balanza de pagos. Cuando la puja distributiva desatada por la inflación cambiaria va reconstituyendo los ingresos urbanos reales, el mercado interno vuelve a expandirse y el tipo de cambio real a atrasarse. Ya están dadas las condiciones para que el ciclo stop and go se reinicie.

${ }^{40}$ Presidencia, Segundo, 1953, p. 279. 


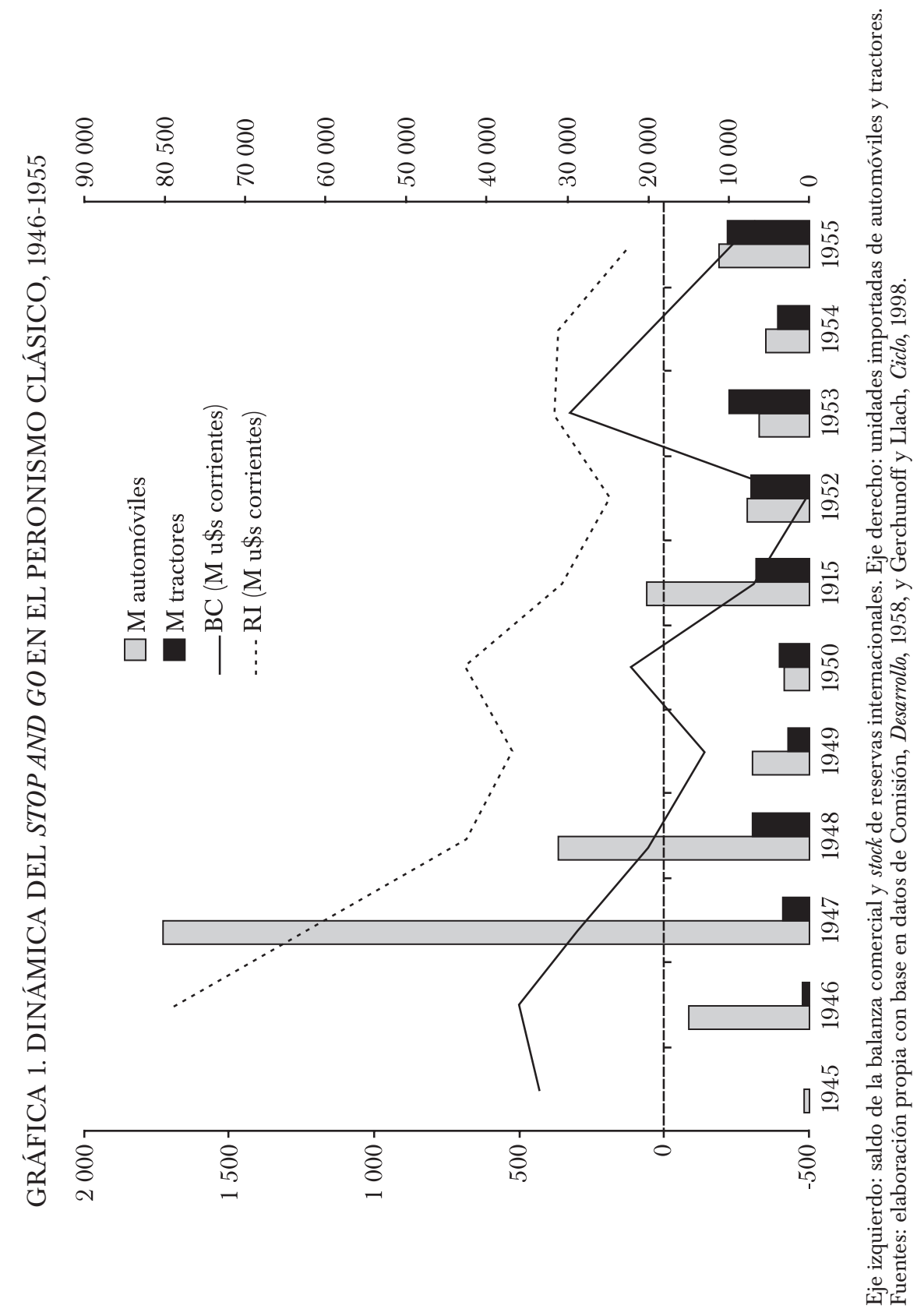


fomentadas en el siguiente orden: siderurgia, metalurgia, aluminio, química, mecánica y eléctrica. Buscando la mayor integración fabril, las ramas alimentaria y textil -las más favorecidas por la política industrial aplicada en el marco del Primer Plan Quinquenal ${ }^{41}$ - pasaron a un segundo plano.

\section{INDUSTRIAS AERONÁUTICAS y MECÁNICAS DEL ESTADO: SE DESPLIEGA EL ABANICO METALMECÁNICO CORDOBÉS, 1952-1955}

Con el estallido de la segunda guerra mundial y el quiebre del comercio internacional, el ingreso de automóviles se interrumpió y la industria local se quedó sin los componentes requeridos para su actividad de montaje; el parque automotor argentino se volvió limitado y antiguo. Acabada la conflagración, la demanda doméstica se volcó por la compra de unidades terminadas del exterior (eclipsando a las unidades ensambladas internamente), convirtiéndose la partida en una destacada fuente de absorción de divisas. Con un pico de 80000 automóviles importados en 1947, el gobierno dispuso restringir las compras externas, estableciendo para ello un riguroso sistema de permisos previos de cambio. Sin embargo, en 1951, restringido el Estado en su disposición de divisas, el ingreso de automóviles extranjeros aumentó más de seis veces respecto al año anterior; peor aún, la demanda interna continuaba estando bastante lejos de ser satisfecha.

A fines de 1951 el presidente Perón se reunió con representantes de importantes automotrices extranjeras para motivarlos a radicar sus plantas en Argentina, en un signo claro de revisión de su postura nacionalista originaria. Pero la propuesta de Perón fue rechazada de plano por los empresarios foráneos. Alegando que el país carecía de condiciones técnicas para desarrollar tal industria, los empresarios foráneos le recomendaron al presidente proseguir con el ensamblado de piezas importadas. Presente en la reunión, el ministro de Aeronáutica y hombre de confianza de Perón, brigadier mayor Juan Ignacio San Martín, ${ }^{42}$ le propuso al presidente fabricar automóviles utilizando las capacidades industriales e ingenieriles existentes en el Instituto Aerotécnico de Córdoba (la ex Fábrica Militar de Aviones). Perón decidió entonces transferirle a la Aeronáutica la responsabilidad de desarrollar la producción automovilística en el marco del

${ }^{41}$ Presidencia, Plan, 1946.

${ }^{42}$ Sobre la destacada trayectoria profesional de San Martín previa a la dirección de IAME, especialmente su reforma de la Fábrica Militar de Aviones y luego su gobernación de la provincia de Córdoba, véanse "Juan Ignacio San Martín, un hacedor de la industria mediterránea", Tiempo de Córdoba, 26 de febrero de 1978; "100 años", 2004; Frenkel, Juan, 1992, pp. 38-40; Bonetto, Industria, 2005, pp. 138-141, y Capelludo, Aproximaciones, 1998. 
Segundo Plan Quinquenal, ${ }^{43}$ función que estaba delegada a la Dirección General de Fabricaciones Militares (en adelante DGFM). ${ }^{44}$

A paso seguido de asignarle a San Martín la tarea del desarrollo automotor, mediante el decreto número 24103 (30 de noviembre de 1951) se crea la Fábrica de Motores y Automotores (luego llamada Fábrica de Automóviles), otorgándosele al instituto un crédito por 60000000 de pesos para la adquisición de licencias y modelos, como para la financiación de los gastos iniciales de explotación. ${ }^{45} \mathrm{Al}$ mes siguiente se inició la construcción de la fábrica y se decretó la promoción y protección de los automotores -y la maquinaria agrícola- bajo el régimen de las "industrias de interés nacional". ${ }^{46}$

El 28 de marzo de 1952, sobre la base de los bienes y personal hasta entonces afectados al Instituto Aerotécnico, se crea por decreto número 6191, Industrias Aeronáuticas y Mecánicas del Estado (véase diagrama 1). Constituida como una empresa autárquica sometida al régimen de la ley número 13653 de Empresas del Estado, ${ }^{47}$ IAME tenía a su cargo:

todas las tareas que desarrolla el Estado nacional relativas a la investigación, estudio, proyecto, construcción, fabricación, reparación, comercialización y distribución de productos utilizados o a utilizar por la Aeronáutica Nacional tanto en sus aspectos civil y comercial, como militar, así como aquellas actividades mecánicas vinculadas directa o indirectamente con su potencial fabril que constituyen un aporte al mejor desarrollo y fortalecimiento de la economía nacional. Además, formará parte de su misión específica, establecer, coordinar, fomentar y promover su acción directa o indirecta, así como con los correspondientes organismos del Estado, en la producción de materias primas utilizables en los procesos industriales a su cargo (art. 2).

Integrándose al grupo de empresas públicas industriales conformadas desde principios de la década de los cuarenta, IAME sería pionera en la fabricación de automóviles en América Latina.

${ }^{43}$ Frenkel, Juan, 1992, p. 97.

${ }^{44}$ Belini, Industria, 2009, p. 63.

${ }^{45}$ Dirección, Reseña, 1968, p. 75.

${ }^{46}$ El decreto número 25056 (12 de diciembre de 1951) estableció por cinco años un régimen de permisos de cambio y liberación de recargos de importación para la introducción de maquinaria y materias primas que demandara el sector automotriz, además del establecimiento de cuotas de importación para restringir la competencia extranjera en caso de que lo requiriera la producción interna.

${ }^{47}$ A partir del 1 de enero de 1953, IAME fue excluida de las previsiones del presupuesto público, debiendo atender sus gastos con los ingresos generados por su propia producción y, en menor grado, con los pagos por parte del Ministerio de Aeronáutica de los proyectos y trabajos de reparación encomendados. No obstante, en el mismo año el Banco Industrial la puso bajo su ala crediticia. 

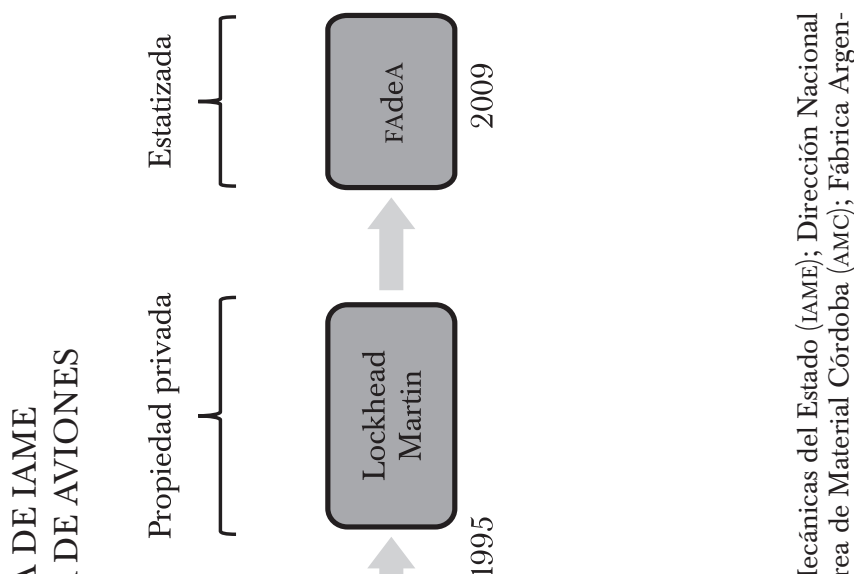

․ㅛ

$\sum_{0}^{\pi} \frac{\pi}{0}$

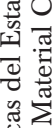

봉

选

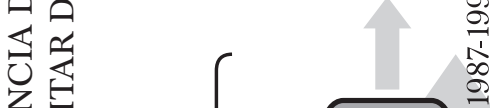

啳

孚

齐这

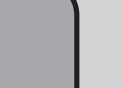

음

또 의

$1<$

동

긍동

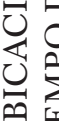

分

단

库空

岁岕
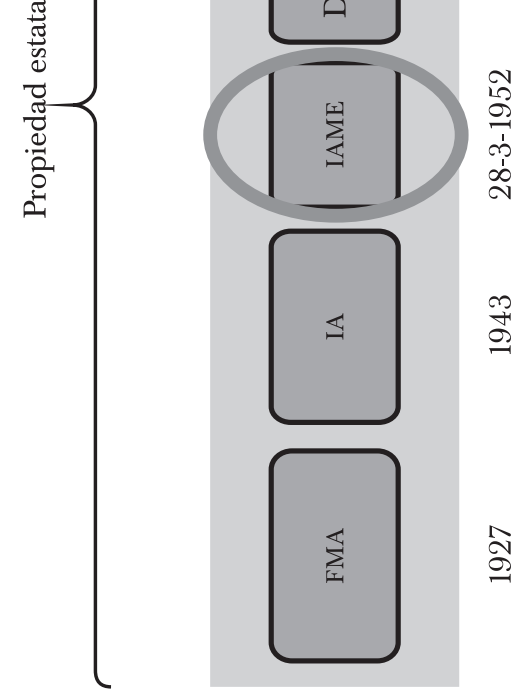

હీ

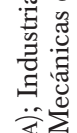

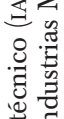

응

突

总

量

空壳

过

完

造密

毠

志充

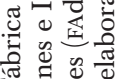

空

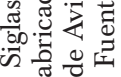
옴 
Los primeros vehículos diseñados se construyeron en tres meses, para ser exhibidos en Buenos Aires en el Día del Trabajador del 1 de mayo de 1952. ${ }^{48}$ Tres vehículos fueron presentados: $:^{49}$ un sedán de dos puertas para cuatro personas (el Institec); un "camioncito para cargas" (la Justicialista Pick Up o Chatita Institec) y una rural (la Justicialista Rural). ${ }^{50}$

A través del Sedán Institec o Justicialista, IAME inició en 1954 la primera producción automotriz en serie -línea interrumpida en 1956-, aunque a escalas bastante inferiores a las correspondientes a un patrón de fabricación fordista. El automóvil fue diseñado íntegramente por ingenieros aeronáuticos argentinos, copiándose las mecánicas del alemán Dampf-KraftWagen (DKW). Estaba equipado con el primer motor automotor de diseño nacional, el IAME 700. Este motor de dos cilindros equipó el 86\% de los sedanes vendidos por IAME, ${ }^{51}$ además de los camioncitos y furgones.

En 1952 también fueron desarrollados los primeros dos prototipos del utilitario Rastrojero. Presentado en julio de 1953, el camión liviano Rastrojero fue diseñado para darle provecho a una partida de tractores estadunidenses Empire comprados por el Instituto Argentino de Promoción del Intercambio, los cuales habían resultado inservibles para el trabajo rural. Así fue creado el Departamento de Recuperación de Tractores Empire, donde se combinaron las piezas de los Empire, con motores a nafta Willys importados y repuestos argentinos. A partir de los Empire, se fabricaron cerca de 2500 Rastrojeros Willys. Desde 1954 se comenzó a fabricar el Rastrojero con motores diesel, primero importados de la empresa alemana Borgward y luego comprados en la filial argentina de esta firma -donde IAME tendría participación en su capital. El Rastrojero Diesel resultó todo un éxito; hacia 1955 se producían más de 3000 unidades. ${ }^{52}$

El decreto número 25056 de 1951 dispuso el establecimiento de permisos y cupos a la entrada de tractores importados. El Estado proyectaba entonces encarar la producción local de tractores, donde se estimaba que IAME tendría la capacidad de producir 4000 unidades anuales, una osada presunción hecha con base en el armado de unos 300 tractores Fiat 55.

${ }^{48}$ Ese día, desde el balcón de la Casa Rosada, un exultante Perón pronunció: "Que nadie se engañe: la economía capitalista no tiene nada que hacer en nuestro país. Sus reductos todavía en pie serán objeto de implacable destrucción.” E iba mucho más allá del capitalismo de Estado: “por una natural evolución de nuestro sistema económico, los trabajadores adquirirán progresivamente la propiedad directa de los bienes capitales de la producción, del comercio y de la industria". No obstante, "el proceso evolucionista será lento y paulatino". Feinmann, Peronismo, 2010, t. I, p. 120 .

49 "Por la buena”, 1952.

${ }^{50}$ Dos rurales más surgirían, el Justicialista Furgón en 1953, y la Gauchita en 1955 (en tan sólo seis unidades).

${ }^{51}$ En 1953 se diseñó un motor de cuatro cilindros, el IAME 800. Dirección, Reseña, 1968, p. 77.

${ }^{52}$ Ibid., p. 76. 
El peronismo se proponía no sólo contribuir al ahorro de divisas, sino también acrecentar su stock al estimular la mecanización agraria. En agosto de 1952 IAME firmó un contrato con la Fabbrica Italiana Automobili di Torino (FIAT) para montar una fábrica de tractores con el fin de "producir por sí y en cooperación con la industria privada tractores integramente argentinos" (decreto número 4075/52). Con sólo tres meses dados por Perón para fabricar un prototipo de tractor, IAME procedió a una reconversión muy limitada del tractor alemán Lanz Bulldog. Así, en octubre de 1952 nació el Pampa, un tractor de dos tiempos semidiésel monocilíndrico de $55 \mathrm{CV}$. Pese a sus imperfecciones técnicas, el Pampa era un tractor de gran simplicidad para las tareas agrícolas. En 1953, IAME elaboró un plan con el objetivo de fabricar 2500 unidades del Pampa, impartiendo órdenes de producción de partes a diferentes empresas metalúrgicas del país.

Para que la "pudieran usar muchos argentinos", IAME fabricó la primera unidad motociclística argentina (en adelante PUMA) en octubre de 1952, un desarrollo inspirado en la motocicleta alemana Guericke. En mayo de 1953, IAME crea la fábrica de motocicletas (decreto número 9170), en la cual se efectuaría el montaje final de los componentes fabricados por la industria privada -la filial de la italiana Gilera sería la mayor proveedora de las 2000 piezas que componían la motocicleta PUMA. Aun sin ser de gran sofisticación, el menor precio de la PUMA primera serie respecto a las otras motocicletas del mercado (en una diferencia de 30\%) provocó un auge de las ventas internas, llegándose a producir hasta 1956 más de 10000 unidades. ${ }^{53}$

En 1953 IAME lanzó otro modelo de automóvil, el Justicialista Gran Sport, de mayor lujo (por ser deportivo o coupé) que los anteriores. El Justicialista Gran Sport contaba con una carrocería de plástico reforzado con fibra de vidrio ${ }^{54}$ lo que hizo de Argentina el segundo país en aplicar esta tecnología. Mientras que el Pre Serie y el Special contaban con un motor Porsche, el resto de los Gran Sport estaba equipado con el mayor desarrollo del Laboratorio de Ensayos de Motores, el motor modular de refrigeración a turbina IAME V-8. En el paroxismo de la inventiva y la afuncionalidad, también se desarrolló el Aerocar, un automóvil propulsado con una hélice de avión completamente expuesta, del que se sugirió fabricar en serie, pero cuyo proyecto se canceló en 1955 por su evidente peligrosidad para el tránsito urbano.

La estructura organizativa de IAME, para 1953, ya se descomponía en diez fábricas que alojaban las diferentes producciones metalmecánicas:

${ }^{53}$ Dirección, Reseña, 1968, pp. 77-78; Arreguez, Fábrica, 2008, pp. 163-164, y Bonetto, Industria, 2005, 187-190.

${ }^{54}$ Coche a la Vista, año VII, núm. 80, marzo de 1954. 
automóviles, ${ }^{55}$ tractores, motocicletas, aviones, máquinas y herramientas, motores de aviación, motores de reacción, instrumentos y equipos, paracaídas, hélices y accesorios (véase diagrama 2). La estructura se completaba con un departamento de metalurgia, siete departamentos administrativos y diez áreas de estudios y ensayos especiales al mando del Instituto Aerotécnico ${ }^{56}$ ya no más cabeza directriz sino dedicado exclusivamente a la investigación y formación técnica, desempeñando un papel clave para tal objeto la Escuela de Aprendices. ${ }^{57}$

Entre 1953 y 1955 IAME tomó financiamiento del Banco Industrial por más de 600000000 de pesos que le sirvió no sólo para comprar licencias extranjeras, sino especialmente para efectuar compras a cientos de fábricas y talleres. Los créditos del Banco Industrial a IAME se concentraron en 1953 (89\% de la corriente de fondos de los tres años), y en ese año fue la principal empresa beneficiaria de la acción crediticia de la banca pública de fomento, con un préstamo de 533000000 de pesos -la cuarta parte del total de créditos para la industria- y $78 \%$ para la rama de maquinarias y vehículos. ${ }^{58} \mathrm{En}$ los dos años siguientes, los préstamos fueron significativamente menores, redireccionándose el crédito público hacia las subsidiarias de las dos firmas extranjeras instaladas en Córdoba. Para 1954 IAME recibió del Banco Industrial un crédito de sólo 27000000 de pesos (1\% del total prestado y 5\% para el sector). Entre enero y septiembre de 1955, la ayuda financiera a IAME fue mayor (41000 000), pero sólo representó 11\% de la rama y $3 \%$ del conjunto industrial. ${ }^{59}$

Hacia 1953, IAME contaba, entre operarios, técnicos y administrativos, con 9672 personas empleadas -aproximadamente $80 \%$ del personal metalmecánico cordobés-, cuando en 1951 eran aproximadamente 5 500. La planta tenía una superficie cubierta de más de $200000 \mathrm{~m}^{2}$ (dos años atrás se extendía en poco más de $100000 \mathrm{~m}^{2}$ ) y estaba equipada con más de

${ }^{55}$ Anexo a la fábrica de automóviles estaba el Taller de Motonáutica, en donde se realizaron series de lanchas deportivas (Institec) y veleros (Tero) en material plástico y motores fuera de borda (Surubí). "Otra", 1953.

${ }^{56}$ En la subestructura del Instituto Aerotécnico, existían los Laboratorios de la División Proyectos Especiales número III, dedicados, en colaboración con la DGFM, al diseño de motores cohetes (el Tábano), bombas voladoras teleguiadas (la PAT-1) y pulsorreactores. Arreguez, Fábrica, 2008, pp. 173-183.

${ }^{57}$ La Escuela de Aprendices tenía el propósito de organizar el aprendizaje de los menores que deseaban ingresar en la fábrica (muchos convocados de escuelas de diferentes regiones del país). Funcionaba en la modalidad de taller-escuela, donde los alumnos, durante tres años, tenían prácticas en la fábrica por la mañana y asistían por la tarde a diferentes materias teóricas. Se estima que la Escuela de Aprendices de IAME dio formación a más de 1000 obreros. Ibid., pp. 185-187.

${ }^{58}$ Rougier, "Política", 2001, p. 113, señala que "tan extraordinario era este préstamo que sobrepasaba en más de 200000000 las necesidades financieras del Plan Quinquenal para el año 1953 y excedía la órbita de operaciones del Banco Industrial, cuyo capital más reservas ascendía a sólo la mitad del monto prestado".

${ }^{59}$ Ibid., pp. 117-120. 





3000 máquinas-herramientas (en su mayoría máquinas universales útiles para distintos fines, una pequeña cantidad de semiautomáticas y muy pocas automáticas) (véase gráfica 2). ${ }^{60}$

En 1952 las empresas ligadas a IAME eran poco más de 100, pero al año siguiente eran 270 y 320 en 1955 (véase gráfica 3). San Martín, mediante el antiguo integracionismo vertical de la Fábrica Militar de Aviones, fue desarmándose para dar cuerpo a la consigna "desarmo el prototipo y convoco a talleristas" (a la gran mayoría los capacitaron y los financiaron con fondos del Banco Industrial), reservando para IAME las producciones más complejas (chasis, carrocería y motor) y el montaje final de las autopartes privadas. ${ }^{61}$ En este sentido, fue clave la acción del Consorcio Industrial para la Producción Automotriz S. A., empresa dependiente de IAME que realizaba los contratos con las empresas privadas, además de gestionarles aportes de capital, tecnología, personal o asistencia técnica, contable y administrativa. ${ }^{62} \mathrm{El}$ posicionamiento de IAME frente a la industria subsidiaria se cerraba con su participación en el capital accionario de sus principales proveedores: Borgward (motores diesel), Gilera (motopartista), Vianini (engranajes helicoidales) y Forja (llantas y ejes), todas filiales de compañías extranjeras, con excepción de la última, con propiedad del empresario peronista Jorge Antonio. Este desarrollo de empresas mixtas con proveedores, concesionarios y, finalmente, terminales (Fiat Concord e Industrias Kaiser Argentina, como se desarrollará en la siguiente sección), marca un contraste con lo acaecido en la Dirección General de Fabricaciones Militares y el fracaso de sus empresas mixtas para incorporar el capital privado. ${ }^{63}$

En el marco de la crisis de divisas, la carestía de lingotes y aleaciones de aluminio del exterior iba en contra de los proyectos aeronáuticos de IAME, con su prueba más palpable en las trabas para alcanzar un proceso seriado del avión Pulqui II. Un ambicioso objetivo dispuesto por el Segundo Plan Quinquenal de producir 10000 toneladas de aluminio primario para 1957 -aunque sin decir cómo alcanzarlo- ${ }^{64}$ quedó a cargo también de

${ }^{60}$ Área, Libro, 1976.

61 "Por la buena", 1952.

${ }^{62}$ Además de estas funciones con los proveedores locales, el Consorcio Industrial para la Producción Automotriz S. A. estaba encargado de la comercialización de la producción automotriz de IAME y de la adquisición de sus insumos importados.

${ }^{63}$ La Dirección General de Fabricaciones Militares, creada en 1941 por el ingeniero militar Manuel Savio, se había propuesto iniciar la producción de actividades básicas (químicas y siderúrgicas), especialmente a través de la creación de sociedades mixtas entre el capital estatal y privado. Sin embargo, a partir de la muerte de Savio, la figura de la sociedad mixta entró en un eclipse para el caso de la DGFM: no se crearon nuevas empresas, la mayoría de las existentes no cumplieron con sus propósitos productivos originales y la participación estatal adquirió la dominancia de los paquetes accionarios de las firmas ante la falta de interés del capital privado por invertir en sus proyectos estratégicos. Sobre la DGFM, véase Belini y Rougier, Estado, 2008.

${ }^{64}$ Presidencia, Segundo, 1953, cap. XVII, objetivo especial núm. 14. 

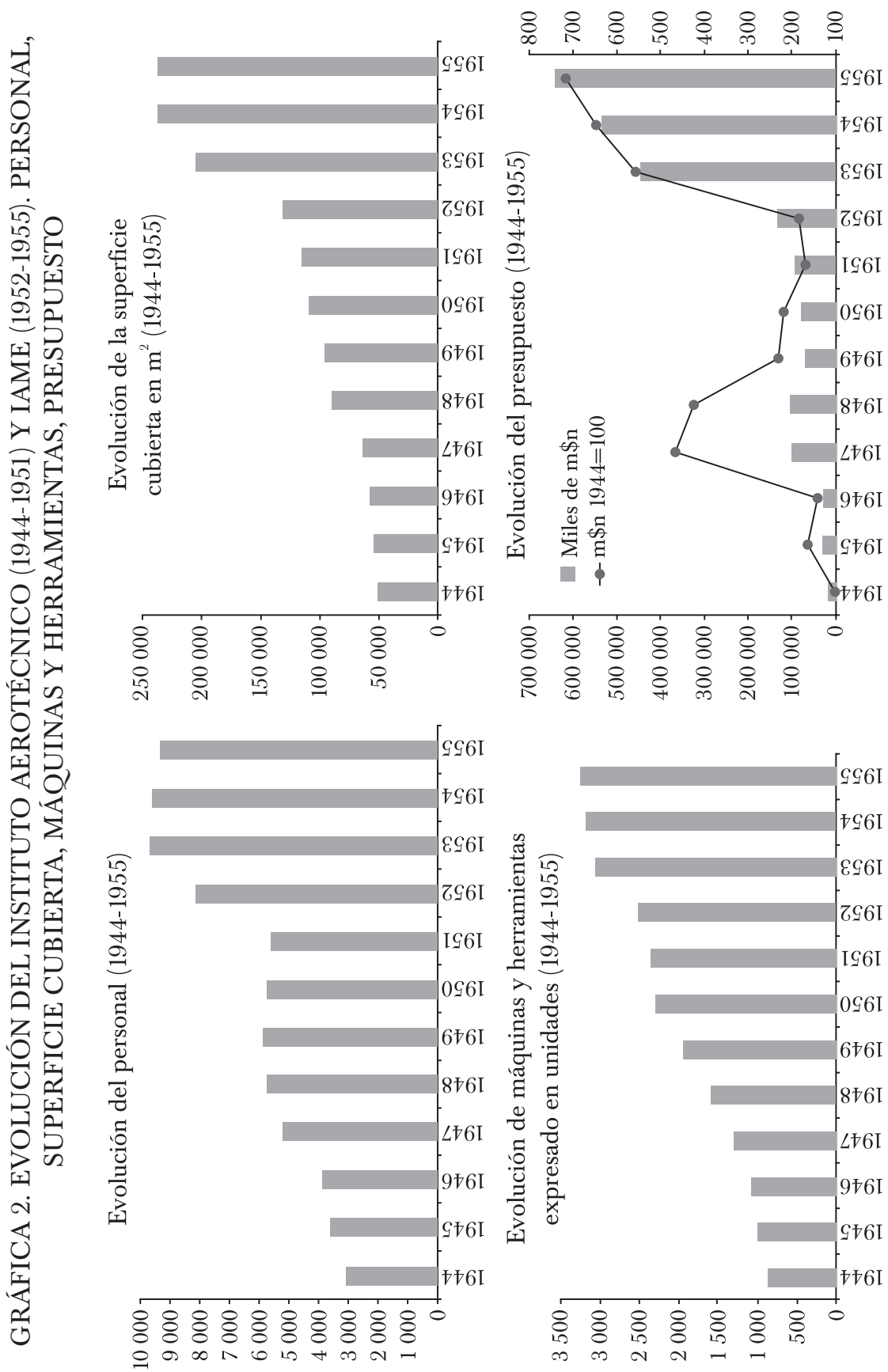

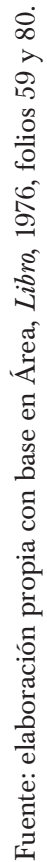




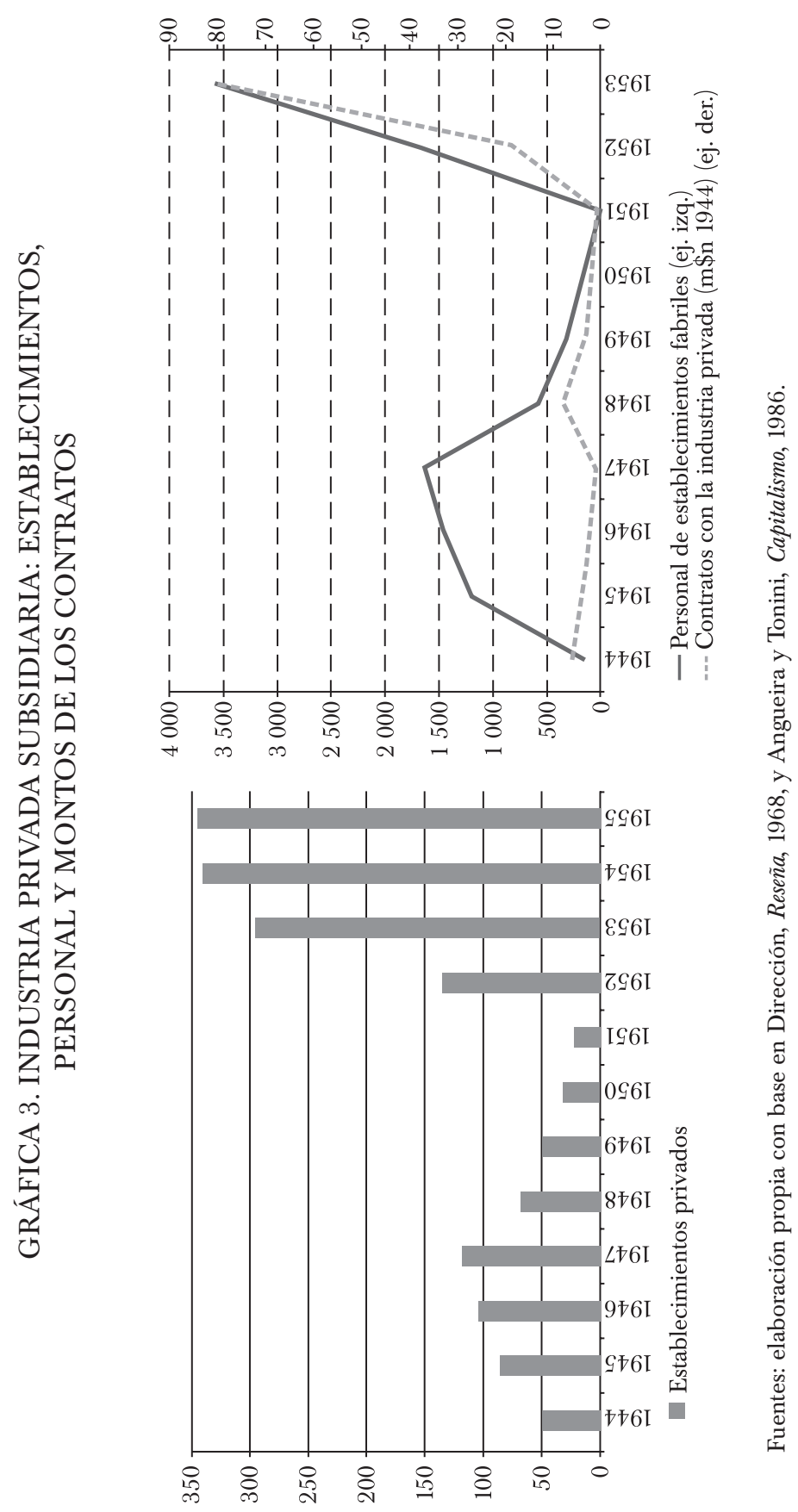


IAME con el concurso de la industria privada -anteriormente la promoción de la industria del aluminio también estaba en las manos exclusivas de la Dirección General de Fabricaciones Militares. IAME proyectó entonces la explotación de materiales aluminíferos y la instalación de una fábrica de aluminio con capacidad de producción de 20000 toneladas por año. ${ }^{65}$ Para ello buscó entablar asociaciones con empresas extranjeras como la americana Kaiser y la Compagnie de Produits Chimiques et Electrometallurgiques del grupo francés Pechiney. ${ }^{66}$ Sin embargo, tales negociaciones terminarían produciendo el golpe de Estado que desplazaría a Perón. Otro objetivo de producción de insumos estratégicos que se propuso alcanzar IAME, sin obtener su concreción tampoco, refería al desarrollo de combustibles y lubricantes usados para la aviación, especialmente aeronaftas, utilizando materia prima nacional. ${ }^{67}$

En materia de producción aeronáutica, la contribución que hiciera la empresa estatal se apoyaría en los lineamientos que incorporara el Segundo Plan Quinquenal de Aeronáutica, ${ }^{68}$ bajo el cual, según promesa de Perón, se completaría la integración nacional de la fabricación de aviones. Sin embargo, al salir este a la luz, resultó ser un documento meramente expositivo, con pocas o casi ninguna referencia a objetivos concretos a apuntar o conductas a sostener. A continuación, se daría paso a una abulia en las políticas fabriles en lo aeronáutico, que se haría patente en el proyecto más avanzado del Instituto Aerotécnico, el I.Ae. 33 Pulqui II. ${ }^{69}$ Pese a ser un emblema peronista en lo discursivo, el Pulqui II no contaría con la posibilidad de entrar a serie en los años restantes del gobierno.

$\mathrm{Al}$ quedar la fabricación de aviones en un práctico estado de stand-by, las mayores contribuciones al desarrollo aeronáutico durante la experiencia de IAME serían la instalación del túnel subsónico para pruebas aerodinámicas $\mathrm{y}$, especialmente, las ideas provenientes del cerebro del alemán Reimar Hörten, el mayor experto en aerodinámica a escala internacional. Sin embargo, sus proyectos tampoco llegarían a serie y sólo algunos prototipos de un modelo de planeador volarían en verdad en vigencia del nuevo plan aeronáutico. Otro proyecto como la instalación de una fábrica de turbinas a reacción (con el que se había firmado un contrato con Rolls Royce en 1950), en la que descansaba la posibilidad de producir un avión

${ }^{65}$ Rougier, "Empeño", 2009, p. 100.

${ }^{66}$ Frenkel, Juan, 1992, p. 131.

67 "Justicialistas", 1953, pp. 34-35.

${ }^{68}$ Ministerio, Segundo, 1952.

${ }^{69} \mathrm{El}$ avión a reacción diseñado por el alemán Kurt Tank, ex director de la Focke-Wulf, era un jet totalmente metálico con alas en flechas (su mayor innovación) y una turbina Rolls-Royce Nene II (uno de los motores más potentes de la época) que volaba hasta alcanzar una velocidad de $1050 \mathrm{~km} / \mathrm{h}$ (mientras su antecesor el Pulqui I de Émile Dewoitine llegaba a los $720 \mathrm{~km} / \mathrm{h}$ ). "El Pulqui”, 1951, pp. 10-13. 
de pasajeros propulsado por turborreactores diseñado por Tank en 1951, también quedaría demorado. ${ }^{70}$

\section{CONTRADICCIONES DESATADAS: IAME Y EL CAPITAL EXTRANJERO}

En la presentación del Primer Plan Quinquenal en 1946, Perón había afirmado: "A nosotros no nos hacen falta capitales, capital tenemos nosotros. Antes que dar preferencia al capital que viene aquí a alzarse con el santo y la limosna, prefiero dárselo a los capitales argentinos que producen acá, que reditúan acá y se quedan en el país." ${ }^{\text {71 }}$ Perón también se refirió a la existencia de dos modalidades de capitalismos: "es menester discriminar entre lo que es el capitalismo internacional de los grandes consorcios de explotación foránea, y lo que es el capital patrimonial de la industria[...] Nosotros hemos defendido a estos últimos y atacado sin cuartel y sin tregua a los primeros. El capitalismo internacional es frío e inhumano[...] es instrumento de explotación y el capitalismo patrimonial lo es de bienestar" -desde la interpretación peronista, este sería el capitalismo ya "humanizado". El 9 de julio de 1947, en el acto por la declaración de la independencia económica, el presidente proclamó entonces "romper los vínculos dominadores del capitalismo foráneo enclavado en el país y recuperar los derechos al gobierno propio de las fuentes económicas nacionales". ${ }^{72}$ Casi un lustro después, el Plan Económico de Austeridad de febrero de 1952 conservaba la misma postura: "la experiencia ha demostrado que no es saludable apelar a esos artificios de que los ahorros de otros pueblos vengan a solucionar nuestras dificultades financieras, por cuanto las inversiones extranjeras[...] en lugar de beneficiosas, resultan perjudiciales". ${ }^{73}$

Sin embargo, a partir de 1953 los hechos barrerían la retórica previa. Arrinconado por la escasez de divisas, el peronismo desconocería su famoso lema "combatiendo al capital", para aguardar la venida del capital extranjero que auxiliara a la no hace mucho economía "independizada". Más allá de la insuficiencia de ahorro interno y de la restricción crediticia para contener la inflación -aunque, como veremos, tal moderación no se manifestaría en los cuantiosos préstamos concedidos a las dos grandes empresas extranjeras que se vincularían con IAME-, se trataba de un problema de divisas. El ahorro en moneda extranjera se presentaba como vía ineluc-

\footnotetext{
${ }^{70}$ Burzaco, “Científicos”, 1995, pp. 8-25.

${ }^{71}$ Rougier, Economía, 2012, p. 63.

${ }^{72}$ Presidencia de la Nación, Acta, 1947.

${ }^{73}$ Rougier, Economía, 2012, p. 144.
} 
table para equipar una industria de base que con su producción pudiera darle continuidad al crecimiento económico.

El Segundo Plan Quinquenal, en orden de establecer y consolidar la industria pesada, determinó la promoción de la radicación de industrias extranjeras como uno de sus objetivos generales para el sector industrial (específicamente el número diez). Tal auspicio incluía la liberación de derechos aduaneros, exenciones impositivas, ventajas cambiarias y créditos para el desenvolvimiento empresario. Su instrumentación debía hacerse "sin perjuicio de los intereses legítimos de las empresas nacionales" ${ }^{74}$, aunque no quedaba claro cómo lidiar con la contraposición de los intereses locales y extranjeros.

En abril de 1953, Perón envió al Congreso un proyecto de ley de inversiones extranjeras. Primera en su tipo, la Ley de Inversiones Extranjeras número 14222 sancionada en agosto de 1953 fue el régimen jurídico en el que se articularía el ingreso del capital externo al sector industrial -sea instalando nuevas plantas o asociándose a existentes- y minero para solucionar el problema de la balanza de pagos. La ley establecía un tratamiento al capital extranjero similar al nacional que permitía luego de dos años la remisión de utilidades de hasta $8 \%$ de su capital y la repatriación de capitales de forma gradual luego de diez años. Además de la exención de derechos aduaneros que ofrecía el Segundo Plan Quinquenal, daba la posibilidad de declararse a la empresa foránea de "interés nacional".

El primer régimen orgánico para las inversiones extranjeras produciría resultados limitados, tanto por el escaso tiempo en vigencia (una circular de 1956 reformaba el sistema), como por la aversión que generaban las restricciones establecidas a la remisión de utilidades y la repatriación de capitales. En el bienio 1954-1955, catorce empresas industriales se instalaron en el país e ingresaron inversiones al sector por 12000000 de dólares -cuando desde el gobierno se deseaba la entrada de 4000 a 5000 millones- $-{ }^{75}$ dos en 1954 y diez al año siguiente, donde los aportes radicados por la Kaiser Motors Corporation fueron de 65\%. Dirigiéndose hacia actividades que absorbían divisas significativamente y que contribuían a una mayor integración, las inversiones extranjeras en la industria se distribuyeron del siguiente modo: $67.3 \%$ en la rama automotriz y tractores; $10.2 \%$ en productos químicos y plásticos; $9.1 \%$ en metalurgia; $5.9 \%$ en petroquímica; $3.4 \%$ en maquinaria agrícola (sin tractores), y $1.8 \%$ en especialidades medicinales. Según su origen (considerando las radicaciones de capital para el conjunto de la economía), 75\% provino de Estados Unidos

\footnotetext{
${ }^{74}$ Presidencia, Segundo, 1953, p. 291.

${ }^{75}$ Peña, Masas, 1971.
} 
de Norteamérica, 13\% de Alemania -entre ellas, Mercedes Benz ${ }^{76}$ las químicas Merck y Monsanto, y Siemens y Bayer que reingresaron luego de ser expropiadas durante la guerra- y 7\% de Italia. Entre 1953 y 1955, el capital extranjero en la fabricación de bienes de inversión y química industrial terminó creciendo 28\% (con un aumento de 47\% para metalurgia y maquinarias). ${ }^{77}$

Por su parte, la ley número 14380 de 1954, modificatoria de la ley número 13653 que regulaba el funcionamiento de las empresas del Estado, dispuso: "la transferencia o enajenación total o parcial del patrimonio de las empresas del Estado, cuando razones de interés general lo justifiquen”. Pero lo anterior en sí no marcaría una contradicción con los principios postulados por el peronismo desde sus primeros años. ${ }^{78}$ Para Perón, las empresas estatales no implicaban el estatismo como estrategia industrial, sino la mera participación del Estado pariendo y asistiendo a sectores industriales cuando no fueran del interés privado. Es más, su deseo no era otro que desprenderse de aquellas empresas. ${ }^{79}$

De lo anterior se desprende que, según la concepción económica del peronismo, el Estado no es el actor empresario estratégico, sino el controlador de los procesos productivos -lo que llevará a discutir cómo es ejercido tal control. Cinco años después del cierre abrupto del peronismo clásico, Antonio Cafiero, ministro de Comercio Exterior entre 1952 y 1954, manifestaría descarnadamente el carácter transitivo y ajeno que tiene el capitalismo de Estado para el peronismo. ${ }^{80}$

Más que un caso hermético de capitalismo de Estado, IAME sería una prueba acabada de la economía mixta que pujó el peronismo. Las con-

${ }^{76}$ Amparada por la ley número 14222 y con el apoyo del Banco Industrial, Mercedes Benz inició la instalación de una nueva planta en Argentina para producir camiones. Con la caída de Perón, este proyecto fue cancelado. Sobre el desembarco de Mercedes Benz, véase Belini, Industria, 2009, pp. 69-73.

${ }^{77}$ Datos en Altimir, Santamaría y Sourrouille, "Instrumentos”, 1967, pp. 370-376.

${ }^{78}$ En su artículo núm. 59, la Síntesis de la doctrina peronista (1948) señalaba: "La economía nacional debe basarse en que el Estado controle los fundamentos de aquella, quedando a la iniciativa privada, a veces en colaboración o en forma mixta con el Estado, o exclusivamente por su cuenta, el desarrollo de la producción y la manufactura de los artículos."

${ }_{79}$ "La industria es una empresa privada, el Estado no tiene ningún interés[...] tan pronto las empresas estatales actuales tomadas en estado de antieconomía puedan ser devueltas a la actividad privada, el Estado tendrá un gran placer en desprenderse de todas esas empresas y entregarlas a los privados. Nosotros somos gobierno, no industriales[...] Nosotros no queremos industrias, porque nos dan mucha pérdida y quizá a ustedes les puedan dar ganancias." "Congreso General de la Industria. La industria argentina en el Segundo Plan Quinquenal”, mayo de 1953.

80 "El estatismo o capitalismo de Estado le es esencial al socialismo y no al justicialismo. Nuestro justicialismo, es verdad, carga una buena dosis de estatismo. Pero tan sólo por imperativo de las contingencias económicas internacionales. No porque lo lleve en la sangre. Y, créame, si no tuviéramos que luchar contra el estatismo internacional y defender al país de la satelización de los imperialismos, echaríamos por la borda nuestra carga de estatismo sin desmedro, antes bien con medro del justicialismo." Cafiero, Cinco, 1961. 
tradicciones que restallaría este conglomerado productivo mixto no vendrían por su aproximación a la iniciativa privada, sino como producto de apoyarse y ceder ante el capital privado extranjero, sobre todo, con qué clase -siguiendo la tipología peronista- de capitalismo foráneo haberse asociado.

El acercamiento de IAME al capital extranjero se potenció con las limitaciones en que incurría la producción automotriz, como aquellas presentadas con los tractores al pasarse de las estimaciones al proceso fabril. Con venia de la autoridad central para valerse de la inversión extranjera para dinamizar el crecimiento industrial, a partir de 1954 IAME buscó formalizar la creación de sociedades, primero con el grupo FIAT y luego con la automotriz Kaiser, donde se entregarían espacios productivos, bienes de capital y recursos humanos -hasta 1957 ambas empresas se limitarían a incorporar la fuerza de trabajo altamente calificada de IAME- con la pretensión de que desarrollaran una producción de mayor escala y eficiencia que satisficiera la demanda interna. San Martín mismo sería el encargado de negociar directamente con las empresas que tomarían la posta en la producción de automóviles y tractores.

En junio de 1954 se inició el montaje del tractor Pampa y a finales de ese mes se entregaron las primeras doce unidades. No obstante, tiempo antes, se había hecho evidente que IAME estaría lejos de satisfacer la demanda interna de tractores (con un déficit de tractorización en el campo calculado en 164000 unidades); el objetivo de abastecer 50\% de la demanda para 1957 (estimada en 20000 tractores) sólo con producción estatal no era factible. Es por eso que en octubre de 1954 el Ministerio de Industria efectuó una licitación pública para que fábricas de tractores se instalasen en el país. Cuatro firmas fueron elegidas para radicarse, tres alemanas y una italiana, FIAT.

La firma de Turín, al poco tiempo de terminar la construcción de la fábrica de tractores de IAME, la adquiere -a un valor menor del que había costado- y la convierte en la Fábrica de Tractores Fiat Someca Construcciones Córdoba. ${ }^{81}$ Para encarar la producción de tractores, en 1954 Fiat recibió un préstamo del Banco Industrial por 285000000 de pesos (un monto tres veces superior al capital de la firma y que representaba más de tres cuartas partes del destinado a la rama de la maquinaria agrícola) y al siguiente de $17000000 .^{82}$ Asimismo, se benefició de un menor tipo de cambio para importar 2000 automóviles, que, al venderlos en el mercado interno a un precio muy por encima del ofrecido en Italia, se hizo de una diferencia sustantiva que funcionaría de capital circulante de la fábrica

\footnotetext{
${ }^{81}$ Fiat, Industria, 1956, pp. 29 y 32, y Angueira y Tonini, Capitalismo, 1986, p. 77.

${ }^{82}$ Rougier, "Política", 2001, pp. 117-118 y 120.
} 
de tractores. La Dirección Nacional de Fabricaciones e Investigaciones Aeronáuticas (DINFIA), la ex IAME, tendría una participación minoritaria en su capital (de 25\% para 1957), cediendo a Fiat todas las instalaciones en octubre de 1959, para continuar produciendo los Pampa en una edificación propia.

Por su parte, la producción de automóviles que IAME estimó desarrollar para 1957 también resultó exagerada. La fabricación en series cortas (como las de los aviones) y con capacidad ociosa, la escasez de divisas para equiparse, la necesidad de conocimientos técnicos especializados en mecánica del automóvil -no alcanzaba con la notable destreza de los operarios e ingenieros aeronáuticos-, la extrema diversidad de los proyectos desarrollados -donde la mayoría no pasaba de la etapa experimental-, la ausencia de especialización de los factores productivos y la industria auxiliar (que IAME bregó por fortalecer) aún en gestación, referían a un esquema automotriz muy diferente al sistema de producción continua y automatizada de los países centrales. ${ }^{83}$

Buscando mercados donde instalar una planta automotriz en asociación con empresas públicas, el empresario estadunidense Henry J. Kaiser entró en contacto con los funcionarios argentinos en agosto de 1954. En un expeditivo proceso de negociación, Industrias Kaiser Argentina (en adelante IKA) quedó organizada a fines de enero de 1955, con un capital inicial de 360000000 de pesos distribuido de esta manera: 32\% para Kaiser (115 000 000), 22\% para IAME y 46\% ofrecido en suscripción pública, quedando en manos extranjeras la mayoría del consejo administrativo. En ese año, el Banco Industrial le concedió a la firma en gestación 228000000 de pesos -a una baja tasa de interés nominal ( $4 \%$ anual) y con extenso plazo de amortización (diez años) - para financiar la construcción de la planta, la adquisición de maquinarias y gastos operativos (el mayor préstamo a una empresa, $20 \%$ del dirigido al sector industrial y $76.5 \%$ para maquinarias y vehículos) ${ }^{84}$ Considerada una empresa de interés nacional, el Banco Central se comprometió a asignarle permisos de cambio por 10000000 de dólares entre 1955 y 1958 para importar máquinas, adquirir autopartes y pagar gastos de ingeniería y dirección de obra. Finalmente, las máquinas que Kaiser aportó a IKA valían en realidad, en función de su antigüedad, $33 \%$ menos de lo que el Estado le terminó reconociendo. ${ }^{85}$

${ }^{83}$ En una entrevista efectuada por la socióloga Ianina Harari, el ingeniero José Monserrat, ex director de la fábrica de automóviles de IAME, al comparar el caso local con una planta automotriz extranjera promedio de la época, declaró: "hablando en criollo, esto era un boliche". Harari, "Crónica", 2007, p. 63. James McCloud percibió a IAME como un colosal "experimento" de un gobierno que subsidiaba la industrialización. McCloud, IKA, 1995, p. 18.

${ }^{84}$ Rougier, "Política", 2001, p. 120.

${ }^{85}$ Belini, "Negocios", 2006, pp. 124-125. 
Para 1958, IKA proyectaba la producción de 20000 jeeps, 10000 sedanes Carabela, 5000 camionetas y 5000 rurales. Por presión de San Martín, la planta fue montada en la localidad de Santa Isabel, ciudad de Córdoba, adonde se trasladó gran parte del acervo físico y humano de IAME. En ese ínterin, estalló el golpe militar del 16 de septiembre de 1955.

Si consideramos en simultáneo los dos casos anteriores surge que las contribuciones de capital propio que hicieron Kaiser y Fiat a sus sociedades resultaron ser de un monto muy inferior al esperado en un principio. Asimismo, como señalan Palmieri y Colomé, la estructura ocupacional de la ciudad de Córdoba no tuvo un cambio significativo entre la desestructuración parcial de IAME (1954-1955) y 1957, en razón de que la única modificación laboral sustantiva fue la privatización, también, de los obreros de IAME. ${ }^{86}$

A pocos meses del golpe de Estado, el mismo Prebisch -partidario de la privatización de IAME como Perón, pero aconsejando transferirla hacia el capital nacional- criticó este tipo de relaciones entabladas por el peronismo con el capital extranjero, acusando a esos "industriales fracasados en otras partes del mundo" que decían ingresar capitales foráneos cuando en realidad lo hacían "a expensas del ahorro del país". ${ }^{87}$

\section{IAME Y LOS RESULTADOS DE LA METALMECÁNICA PERONISTA}

Hacia 1955 la producción industrial continuaba compuesta en su mayoría por bienes de consumo y de uso intermedio, mientras que la participación de bienes de capital sólo era de 6\%, dando la pauta del alcance insuficiente de la política peronista postrera por integrar el tejido industrial. No obstante, el avance de la metalmecánica fue significativo durante el peronismo clásico.

Con base en los censos industriales de 1946 y 1954, Sourrouille y Lucángeli señalan que para la metalmecánica, "en estos ocho años se vuelve a duplicar el número de establecimientos, la ocupación aumenta $60 \%$ frente a $25 \%$ del total (industrial) y supera a la industria alimentaria y a la textil en todos los indicadores, con excepción del valor de producción". ${ }^{88}$ Esta última observación no es más que el reflejo de un hecho notable, el crecimiento de los pequeños talleres, en gran medida dedicados a reparaciones o fabricación de repuestos, con un alto coeficiente de valor agregado por

${ }^{86}$ Palmieri y Colomé, "Industria”, 1965.

${ }^{87}$ Agrupación Reformista de Graduados en Ciencias Económicas, Mesa redonda del Informe Raúl Prebisch celebrada el 28 de noviembre de 1955 en el Aula Magna de la Facultad de Ciencias Médicas.

${ }^{88}$ Sourrouille y Lucángeli, “Apuntes”, 1980. 
unidad de producción. ${ }^{89} \mathrm{El}$ rubro de vehículos, maquinarias y aparatos eléctricos fue el que tomó mayor crecimiento en su participación en la estructura industrial (a expensas de la producción de alimentos, textiles y cuero), pasando de 6.4 a $11.4 \%$ de la producción y de 11.2 a $17 \%$ del empleo (con un aumento de $14 \%$ de su productividad). ${ }^{90}$

Según la Comisión Económica para América Latina y el Caribe (CEPAL), la producción conjunta de metales, vehículos, maquinaria y aparatos eléctricos (a precios constantes de 1950) creció a una tasa anual promedio de $15 \%$ entre 1946 y 1955, donde el aumento por año en el tramo final de 1950-1955 fue de 22\%. ${ }^{91}$ Particularmente, la fabricación de maquinarias y equipos, que entre 1937-1939 era de 280000000 de pesos de 1950 y absorbía 17\% de la demanda, en 1950 alcanzaba 700000000 de pesos con 35\% del consumo, para duplicarse en 1955 y ya reteniendo la mitad del mercado interno. ${ }^{92}$

Traccionada por IAME, la participación de la fabricación estatal de vehículos y maquinarias saltó de 11 a 33\% del total entre 1946 y 1953, y después de la producción de derivados del petróleo fue el sector con mayor peso del Estado empresario argentino (para el concierto industrial, el valor producido por el Estado industrial era poco más de 9\%). En términos de empleo, el Estado ocupaba más de la mitad de los obreros metalmecánicos en 1953 (sólo 19\% en 1946). ${ }^{93}$

Antes de IAME, la fabricación de automóviles era prácticamente inexistente en el país, reducida a procesos de montaje de componentes importados que significaban una porción marginal de la rama de vehículos y maquinarias; en 1951, Autoar, el esfuerzo productivo más importante hasta ese momento, no llegaba a abastecer el 1\% de la demanda automotriz. Entre 1953 y 1955 IAME fabricó casi 10000 automóviles, cada uno con su motor de diseño nacional, contra el centenar de Autoar. No obstante, la práctica totalidad de los vehículos producidos eran utilitarios $(63 \%$ rastrojeros, $27 \%$ chatitas, y $6 \%$ furgones). El Sedán, automóvil destinado a satisfacer las necesidades de transporte de las familias trabajadoras, lejos estuvo de ser un éxito comercial; se produjeron sólo 179 unidades, menos de $1 \%$ de la oferta interna, casi en la misma cantidad que el Justicialista deportivo, un suntuario automóvil, pero poseedor de la moderna tecnolo-

${ }^{89} \mathrm{Ibid}$.

${ }^{90}$ Peña aclara que gran parte de este rubro a mediados de los cincuenta no se componía de bienes de capital, sino de artefactos para el uso doméstico. Peña, Industrialización, 1986, p. 27. El sector de artículos del hogar fue uno de los exponentes más representativos del crecimiento de la metalmecánica durante el peronismo. Para la pujante evolución de este sector durante el peronismo, véase Belini, Industria, 2009, cap. 5.

${ }_{91}$ Comisión, Desarrollo, 1a. parte, 1958, p. 33.

${ }^{92}$ Ibid., 2a. parte, p. 192.

${ }^{93}$ Con base en datos de Belini y Rougier, Estado, 2008, p. 29. 
gía del laminado plástico. En cambio, los utilitarios presentaron niveles de producción remarcables, entre ellos destacó el Rastrojero Diesel, con 30\% del mercado de automóviles para $1955 .^{94}$

Como con la producción motonáutica, IAME fue responsable de originar la fabricación nacional de tractores agrícolas en 1952. Sin embargo, detrás de este orgullo del Estado empresario peronista, se escondía una capitulación a los intereses de la Fiat, reprochada tanto por los obreros como por los tractopartistas de IAME. La producción del Pampa nacería en el preludio a la conformación del oligopolio transnacional de la industria del tractor, y así fue su desempeño en términos de ventas, furtivo como lo había sido para el sedán. Pese al claroscuro de la producción estatal, la política de promoción de la maquinaria agrícola nacida a fines de 1951 se comprobó muy exitosa. De la nada, para 1955 se fabricaban cerca de 5000 tractores, donde se sustituyó casi la mitad de las importaciones. Para los otros subsectores de la maquinaria agrícola, entre 1948 y 1953 la producción de cosechadoras aumentó 149\%, de sembradoras 113\%, de arados $743 \%$ y de rastras $44 \% .{ }^{95}$ Prorrogado a futuro, el régimen de promoción sectorial permitiría completar el proceso sustitutivo, tanto en término de unidades terminadas como de agropartes.

La producción de la motocicleta PUMA, al igual que con los rastrojeros, exhibió un crecimiento exponencial hasta 1955 (tendencia que continuaría por cinco años más), montado sobre la demanda de aquellos que iban "del trabajo a casa y de casa al trabajo". En octubre de 1954, la empresa SIAM de la familia Di Tella -que llegaría a ser la firma metalmecánica más grande de Latinoamérica a comienzos de los sesenta- introdujo la motoneta Siambretta; su atractivo persistió hasta la eclosión de la oferta automotriz a fines de los años cincuenta (véase cuadro 1).

Respecto a la producción originaria de IAME, el entumecimiento en que cayó la fabricación aeronáutica a partir de 1952 se manifestó como la contracara a la efervescencia de las producciones civiles practicadas. La nueva fase de la Fábrica Militar de Aviones se irguió sobre los hombros de la industrialización aeronáutica previa, hasta el punto de abatirla. Observándose el cuadro 2, mientras que en el Primer Plan Quinquenal de Aeronáutica ${ }^{96}$ se construyeron 212 aviones, en el Segundo Plan Quinquenal sólo se hicieron nueve aeronaves -ninguna en 1955. De los diseños de Tank, se construyeron dos nuevos prototipos del Pulqui II y dos Justicialistas del

${ }^{94}$ La producción de camiones fue uno de los sectores que surgieron durante el peronismo. De no existir un proceso productivo a comienzos de los cincuenta, en 1955 se producían más de 1600 camiones, representando la cuarta parte de las unidades comercializadas. Belini, Industria, 2009 , p. 81.

${ }_{95}$ Ibid., pp. 120 y 106.

${ }^{96}$ Secretaría de Aeronáutica, Plan, 1946. 


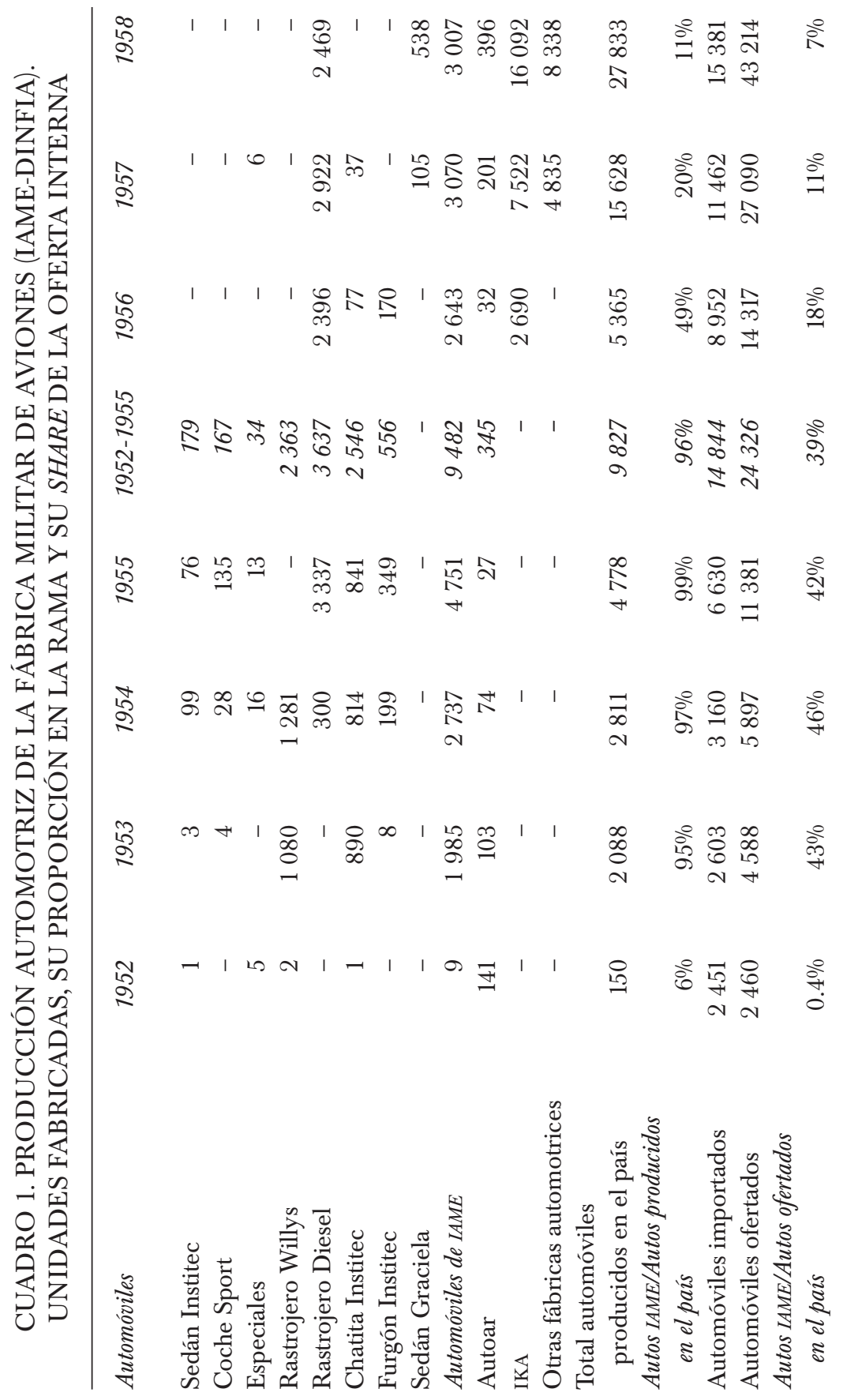




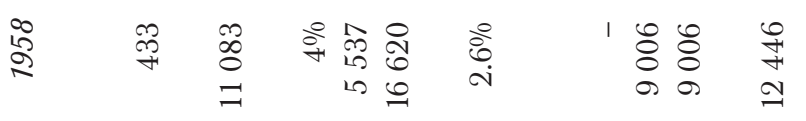

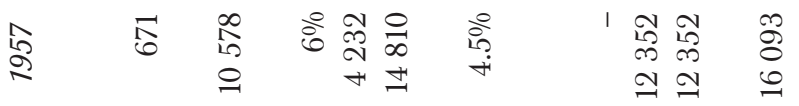

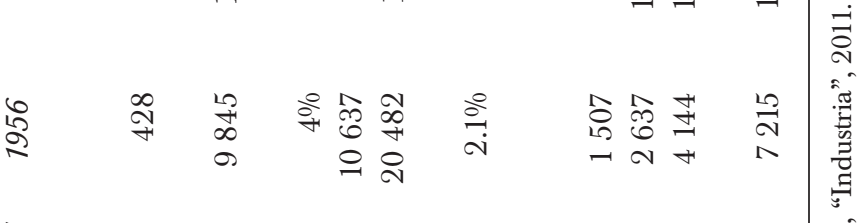

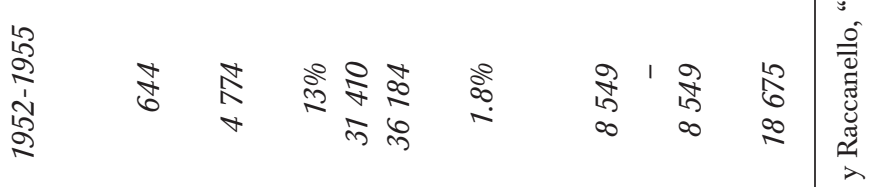

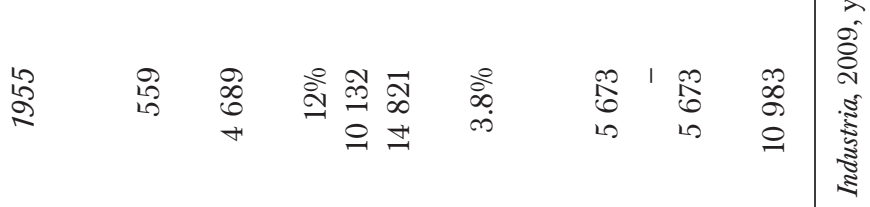

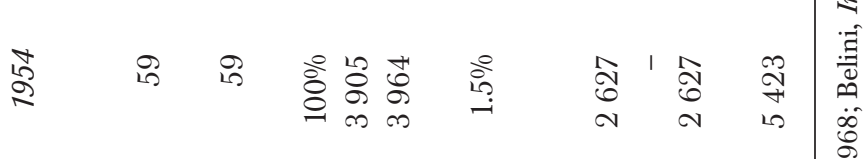

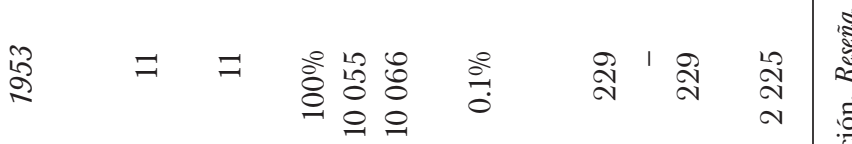

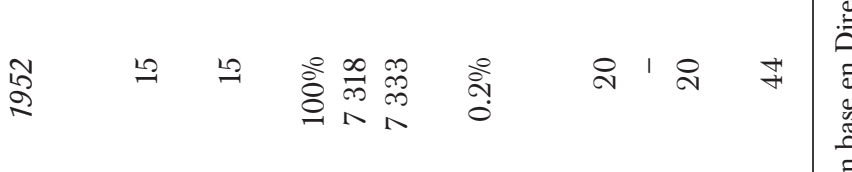

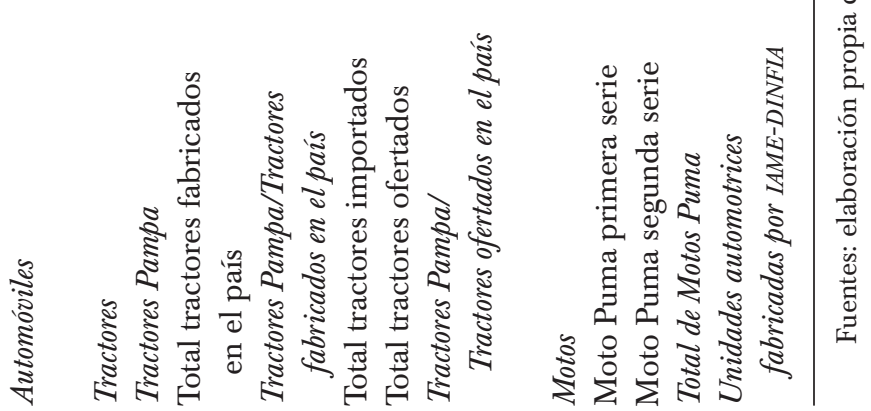




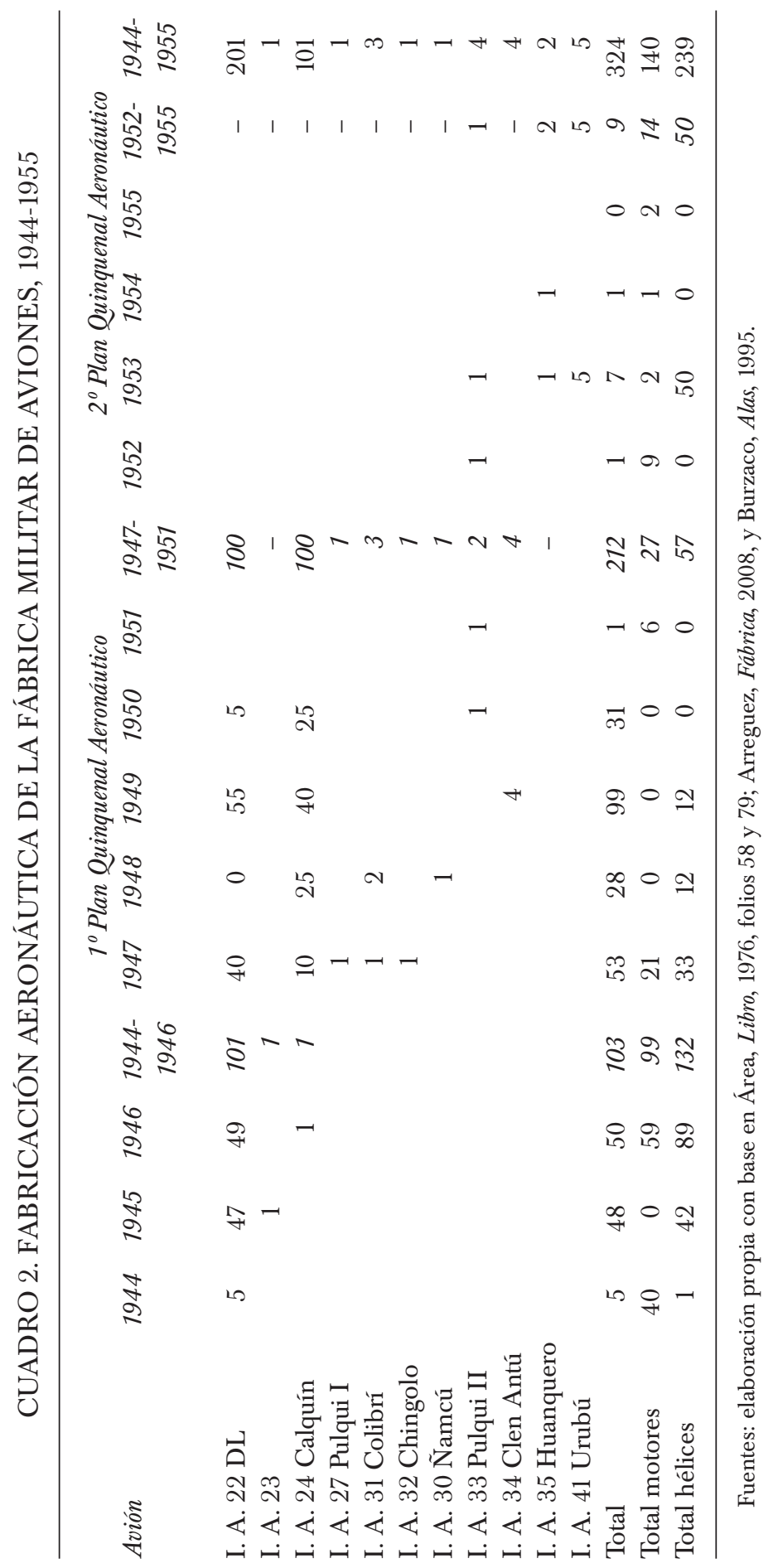


aire, monoplanos metálicos bimotor multipropósito I. A. 35. De parte de Hörten, entre 1949 y 1955 sólo se pudo dar término a la fabricación de cinco planeadores deportivos de madera solicitados por aeroclubes subvencionados por el gobierno. La industria aeronáutica quedaba acotada a la fabricación de hélices y motores (de menor cuantía en relación con el pasado reciente) como a tareas de reparación de aviones y sus partes. Ya desde 1954, desde las publicaciones oficiales se afirmaba que IAME se restringiría al diseño de prototipos avanzados -sucediendo lo mismo con los motores de los aviones-, sin proceder a la producción seriada debido a los altos costos de los aviones y su pronta obsolescencia -no quedando en claro entonces el sentido económico o de defensa de aquellos gastos de investigación. ${ }^{97}$

Siguiendo a Artopoulos, fueron numerosos los factores que colaboraron en la postergación que hizo el peronismo para la entrada en serie de su mayor creación tecnológica, el Pulqui II de Kurt Tank. Pero los más relevantes fueron la escasez de divisas para insumos estratégicos (especialmente aluminio) y el apoyo notablemente menor por parte de Perón a la fabricación aeronáutica -comprimiendo su partida presupuestariaatribuido a ese nuevo "berretín" con las nuevas producciones mecánicas.

El potencial de Reimar Hörten también se vio contenido por las circunstancias coyunturales. Hörten tenía deseos de construir un caza a reacción que superara al Pulqui II (con mayor velocidad, menor velocidad de aterrizaje y mayor techo de servicio); sin embargo su proyecto fue archivado para concentrar los recursos en la creación de Tank ya presentada a Perón. Las otras adversidades que enfrentó fueron la falta de materiales básicos a la que debió ajustarse y hasta las actitudes proselitistas del gobierno ${ }^{98}$ todo en el marco del cambio en la orientación productiva que se dio con la creación de IAME. Después de concebir el Clen Antú de 1949, Hörten estuvo dedicado a tres proyectos que, al final de cuentas, nunca adquirirían un proceso de fabricación en serie. En suma, Hörten, quien había diseñado en Alemania un avión de guerra que se adelantaba en décadas a la tecnología aeronáutica de la época, sólo completó entre 1948 y 1955 nueve planeadores deportivos sin motor.

\footnotetext{
97 "Rodando", 1954, p. 39. En Conradis, Forschen, 1959, Tank señala: "los alemanes fuimos contratados para desarrollar prototipos, no para montar una industria aeronáutica".

${ }^{98}$ Horten y Selinger, Nurflügel, 1983.
} 


\section{CONCLUSiOnes}

El conglomerado IAME consiguió ser un terreno fértil para la experimentación industrial. De los ensueños surgidos tempestivamente en la cabeza del Estado (los autos, las motos, el tractor), San Martín los satisfizo dando rienda suelta a la capacidad creadora de sus ingenieros -más de una vez quedando en segundo plano la funcionalidad económica-, acreedores de la carta blanca de la prueba y el error. San Martín incubó el desarrollo de capacidades técnicas endógenas como garantía de la innovación futura: aquellas capabilities forjadas en la fabricación e investigación aeronáutica se reconfigurarían con la producción automotriz estatal para luego transferirse al proceso seriado comandado por el capital extranjero. IAME entonces, sería un ámbito socioproductivo cruzado por las externalidades entre cada una de las células que lo componían, donde procesos de learning by doing quedaban enlazados a conocimientos teóricos brindados por dependencias internas tales como la Escuela de Aprendices.

En sí, IAME no podría considerarse un verdadero exponente de la racionalidad económica que debían poseer las nuevas actividades industriales a radicarse en la estructura económica, ya que sus rasgos artesanales abundaban por doquier. La enorme destreza y multifuncionalidad de sus operarios eran signos visibles de una escasa división del trabajo al interior de una organización distante al sistema fordista de producción automotriz. IAME se comprometió a una producción seriada de automóviles que a duras penas se acercó. Aunque con ciertas excepciones como el Rastrojero o la PUMA, lo suyo era el diseño y creación de prototipos más que el desarrollo fabril, parte porque se pretendía así, parte por ausencia de recursos y de mayor voluntad política.

Pese a su carácter advenedizo -por la motivación particular que le dio origen-, el gris rendimiento para satisfacer la demanda interna o el conjunto de ineficiencias productivas que acumuló, en su efímero ciclo de vida IAME se atrevió a incursionar en actividades inexistentes en Argentina o que no iban más allá del ensamblaje de componentes importados. Más que su producción terminal, el mayor mérito de IAME fue alumbrar una red de proveedores autopartistas que, aun en su insuficiencia, sería clave para las futuras empresas automotrices radicadas en la economía sustitutiva local. Por este enlazamiento con los proveedores privados, IAME fue el complejo económico estatal-privado, o mejor dicho, el complejo militarindustrial de la metalmecánica peronista. ${ }^{99}$

La actuación del Estado en el caso IAME tuvo puntos de contacto con varias de las recomendaciones de los teóricos del desarrollo presentadas a

${ }^{99}$ Schvarzer, "Empresas”, 1979; Galbraith, Nuevo, 1967, y Rougier, "Militares", 2011. 
comienzos del trabajo. Ante la ausencia inicial de disposición empresaria para la aventura automotriz (como se vio, a ninguna empresa automotriz se le cruzaba la idea de construir su propia red autopartista en Argentina, como tampoco probar suerte por sí sola en un contexto de fuerte restricción de divisas). A través del big push que significó la creación de IAME, el Estado peronista enfrentó las fallas de mercado existentes al iniciar el montaje de una nueva industria y tendió eslabonamientos hacia atrás para alumbrar una industria autopartista. ${ }^{100}$ Por su parte, el Banco Industrial, al menos en un principio, movilizó cuantiosos fondos financieros para estos propósitos. ${ }^{101}$ Asimismo, la conformación de IAME consolidó a la ciudad de Córdoba como polo de crecimiento, desplegando las fuerzas productivas de su periferia: el flujo inversor (básicamente estatal), la concurrencia de recursos humanos y la apertura de proveedores se sintetizaron en un crecimiento económico retroalimentado ${ }^{102}$ en sintonía con la lógica de la causación circular acumulativa de Myrdal. ${ }^{103}$

En cambio, pese al estímulo estatal a la sustitución de importaciones que implicó IAME, la experiencia no contó con el beneplácito de Prebisch: los escasos rasgos de racionalización económica en un sector al cual consideraba poco estratégico para solucionar el problema de la brecha externa $^{104}$ eran suficientes motivos para bajarle el pulgar a esta experiencia industrial.

Discutir la cuestión de si en IAME se observó el comportamiento de un Estado schumpeteriano se vuelve más complejo. La innovación radical en lo aeronáutico se sustituyó por la innovación incremental de la metalmecánica, ${ }^{105}$ menos ambiciosa pero con mayores externalidades hacia lo económico. Más adelante, la delegación de la industria automotriz y de tractores a la industria privada en principio buscó acelerar la incorporación tecnológica, pero finalmente terminó siendo poco satisfactoria en función de las abundantes prebendas y licencias que se concedieron a IKA y a Fiat.

IAME representó la conjugación de varias bisagras de la historia industrial argentina: el alumbramiento de la segunda fase de la sustitución de importaciones, la apuesta por el capital extranjero -un desarrollismo peronista pero sin la densidad estratégica del desarrollismo del tándem

${ }^{100}$ Rosenstein-Rodan, "Problems", 1943; Ferrer, Estado, 1956, y Hirschman, Strategy, 1958.

${ }^{101}$ En palabras de Perón de 1952: "La industria privada no podía ponerse en esto porque se necesitaban muchos capitales, muchas decisiones y era exponerse a perder unos pesos y las empresas privadas no están en esto siempre tan decididas como nosotros." Mundo Peronista, núm. 21, año I, mayo de 1952. Véase también Gerschenkron, Economic, 1962.

${ }^{102}$ Boudeville, Problems, 1966.

${ }^{103}$ Myrdal, Economic, 1957.

${ }^{104}$ Prebisch, Moneda, 1956, p. 52.

${ }^{105}$ Artopoulos, Tecnología, 2012. 
desarrollista Frondizi-Frigerio-, el eclipse de la industria militar frente a la civil. Asimismo, marcó las contradicciones intrínsecas, pero coherentes, a la lógica económica peronista.

IAME fue signo de la cristalización del cambio de rumbo económico que se inició en 1949 donde, además de la actividad rural, las industrias básicas y pesadas comenzaron a tomar gravitación para el peronismo. Pero sobre todo, representó el desgarramiento definitivo de la bandera nacionalista de los primeros años. Peor aún, la conformación al interior de su alianza sociotécnica de "ámbitos privilegiados de acumulación"106 para IKA y Fiat, indican que, al menos en estos casos, el peronismo favoreció a los grandes consorcios de explotación foránea y no al capital patrimonialista.

Como un uróboro, IAME comienza (convocatoria frustrada de fines de 1951) y termina (desembarco de Fiat y Kaiser en 1954-1955) con el capital extranjero; su transitoriedad fue de origen y permanente su potencial de plataforma de aterrizaje de las inversiones foráneas - prueba de ello su alianza tecnológica con Fiat a mediados de 1952. En este sentido, el conglomerado peronista no puede considerarse un fruto del tecnonacionalismo como lo fue Yacimientos Petrolíferos Fiscales (YPF) de Mosconi o la Dirección General de Fabricaciones Militares de Savio, sino a lo sumo una experiencia tecnointernista que, pese a endogeneizar capacidades técnicas locales, no terminó de forjar un proceso de desarrollo tecnoproductivo -la limitada cantidad de automóviles y tractores producidos ya son pruebas suficientes- pero sí de constituir y densificar una base tecnoproductiva. Ahora, si entendemos por tecnonacionalismo el control efectivo de las alianzas sociotécnicas, tampoco pareciera comprobarse ante los enraizamientos que las corporaciones extranjeras van tejiendo con un Estado que, en declinación de su autonomía, accede y avala sus demandas (alejando al Estado peronista de la figura de Estado desarrollista). IAME entonces, va corriéndose de la centralidad de la alianza sociotécnica aun antes del golpe de Estado, asemejándose con el futuro esquema desarrollista en su dependencia tecnológica, pero con la diferencia en términos de grado respecto a incorporación técnica. En consecuencia, IAME terminó contribuyendo a la autarquía pero no a la autonomía de la economía argentina. En el marco de un reforzamiento de la seudoindustrialización argentina, IKA y Fiat operaron como pioneros de lo que Schvarzer denominó "industrialización por desborde de las empresas transnacionales de su mercado local". ${ }^{107}$

Por último, IAME fue un momento económico en la dinámica maniobrada siguiendo la lógica económica peronista, no mejor explicada que por el mismo Perón:

${ }^{106}$ Castellani, “Ámbitos”, 2011.

${ }^{107}$ Peña, Masas, 1986, y Schvarzer, Industria, 2000, p. 222. 
Nosotros no somos intervencionistas ni antiintervencionistas, somos realistas. El que se dice "intervencionista" no sabe lo que dice; hay que ubicarse de acuerdo con lo que exigen las circunstancias. Las circunstancias imponen la solución. No hay sistemas ni métodos ni reglas de economía en los tiempos actuales. Hay soluciones concretas frente a un problema también concreto. Resuelto ese problema se va a presentar otro quizá, también diametralmente opuesto al anterior. A este le daremos una solución contraria a la anterior, pero no por sistema, sino por inteligente apreciación y reflexión del caso concreto [...] No hay sistemas económicos sino momentos económicos. ${ }^{108}$

Pese a transcurrir la mayor parte de su breve existencia en el marco del Segundo Plan Quinquenal, IAME no emergió como instrumentación táctica de una estrategia de transformación estructural de largo plazo constitutiva de la concepción económica del peronismo. IAME en verdad fue concebido sobre la marcha de la economía, como una ruta de escape transitoria y forzosa que el peronismo tomó improvisadamente para descomprimir la trampa de la escasez de divisas. En IAME hay lectura de la realidad, reflejos y aplicación de praxis puntuales; un instante de sublimación pragmática inherente a la lógica económica peronista.

\section{FUENTES CONSULTADAS}

\section{Hemerografía}

Tiempo de Córdoba, Córdoba, Argentina.

\section{Bibliografia}

“A 100 años de su natalicio: brigadier mayor Juan Ignacio San Martín”, Aeroespacio, Fuerza Aérea Argentina, núm. 561, septiembre-octubre de 2004, Argentina.

Altimir, Oscar, Horacio Santamaría y Juan Sourrouille, "Los instrumentos de promoción industrial en la posguerra”, Desarrollo Económico, Instituto de Desarrollo Económico, vol. 7, núms. 25-27, abril-diciembre de 1967, pp. 893-918, 149-172 y 361-376, respectivamente.

Angueira, María del Carmen y Alicia del Carmen Tonini, Capitalismo de Estado (1927-1956), Buenos Aires, Consejo Editor de América Latina, 1986.

${ }^{108}$ Rougier, Economía, 2012, pp. 178-180. 
Ansaldi, Waldo, "Córdoba: de la protoindustria a la gran industria dependiente 1946-1954”, Estudios e Investigaciones, Fundación para el Estudio de los Problemas Argentinos, vol. 1, núm. 2, agosto de 1979, pp. 20-32.

Área de Material Córdoba, Libro histórico, 1926-1976, Buenos Aires, Fuerza Aérea Argentina, 1976.

Arreguez, Ángel C., Fábrica militar de aviones: crónicas y testimonios, Córdoba, Agencia Córdoba Ciencia, 2008.

Artopoulos, Alejandro, Tecnología e innovación en países emergentes: la aventura del Pulqui II (1947-1960), Buenos Aires, Lenguaje Claro Editora, 2012.

BASUALDO, EDUARDO, "Los primeros gobiernos peronistas y la consolidación del país industrial: éxitos y fracasos", Cuadernos del Centro de Estudios del Desarrollo, Universidad Central de Venezuela, vol. 22, núm. 60, pp. 113-151, septiembre-diciembre de 2005.

Belini, Claudio, "Política industrial y sustitución de importaciones: el caso de la industria de maquinaria agrícola, 1951-1957”, XIX Jornadas de Historia Económica de la Asociación Argentina de Historia Económica, San Martín de los Andes, Universidad Nacional del Comahue, 2004.

"Negocios, poder y política industrial en los orígenes de la industria automotriz argentina, 1943-1958", Revista de Historia Industrial, Universitat de Barcelona, vol. 2, núm. 31, año XV, 2006.

, La industria peronista. 1946-1955: políticas públicas y cambio estructural, Buenos Aires, Edhasa, 2009.

y MARCelo Rougier, El Estado empresario en la industria argentina: conformación y crisis, Buenos Aires, Manantial, 2008.

Bonetto, Walter, La industria perdida, Córdoba, Fojas Cero Editora, 2005.

Boudeville, JaCQues, Problems of regional economic planning, Edimburgo, Edinburgh University Press, 1966.

Burzaco, Ricardo, Las alas de Perón, Buenos Aires, Editorial Da Vinci, 1995.

, "Los científicos alemanes y Perón”, Todo Es Historia, núm. 334, mayo de 1995, Argentina, pp. 8-25.

Cafiero, Antonio, Cinco años después, Buenos Aires, Eudeba, 1961.

CaPelludo, Rafael, Aproximaciones al gobernador San Martín, Córdoba, Secretaría General de la Gobernación, 1998.

CASTEllani, ANA, "Ámbitos privilegiados de acumulación y restricciones al desarrollo. La relación Estado/empresarios en la Argentina (1966-1989)”, VI Congreso Chileno de Sociología, Universidad de Valparaíso, 2011.

Censo industrial, Buenos Aires, Dirección Nacional del Servicio Estadístico, años 1946, 1950 y 1954.

Chandler, Alfred, Strategy and Structure. Chapters in the History of the Industrial Enterprise, Nueva York, Doubleday \& Co./Anchor Books, 1966 [1962]. 
Chávez, Fermín, “IME: Industria y tecnología nacional también es soberanía”, Realidad Económica, Instituto Argentino para el Desarrollo Económico, núm. 38, eneromarzo de 1980.

COMISIÓn ECONÓMICA PARA AMÉRICA LATINA y EL CARIBe, El desarrollo económico de la Argentina, Santiago, Comisión Económica para América Latina y el Caribe, 1a. y 2a. partes, 1958 .

Conradis, Heinz, Forschen und Fliegen. Weg und Werk von Kurt Tank, Alemania, Musterschmidt, 1959.

Díaz Alejandro, Carlos, Ensayos sobre la historia económica argentina, Buenos Aires, Amorrortu, 1975.

Dirección Nacional de Fabricaciones e Investigaciones Aeronáuticas, Memoria y balance general, años 1957, 1960-1961, 1962-1963, 1965. Reseña histórica de la Dirección Nacional de Fabricaciones e Investigaciones Aeronáuticas en su 40 aniversario. 10 de octubre. 1927-1967, Buenos Aires, La Dirección, 1968.

"El Pulqui II hizo su presentación oficial jugándole carreras al sonido", Revista Nacional de Aeronáutica, Círculo de Aeronáutica, año XI, núm. 107, febrero de 1951, Buenos Aires, pp. 10-13.

Evans, Peter, "El Estado como problema y solución”, Desarrollo Económico, Instituto de Desarrollo Económico, vol. 35, núm. 140, enero-marzo de 1996, pp. 529-562.

Feinmann, José Pablo, Peronismo. Filosofía politica de una persistencia argentina, Buenos Aires, Planeta, 2010, t. I.

Ferrer, Aldo, El Estado y el desarrollo económico, Buenos Aires, Editorial Raigal, 1956.

Fiat Someca Construcciones Córdoba Concord, La industria del tractor en la Argentina, Buenos Aires, s. e., 1956.

Frenkel, Leopoldo, Juan Ignacio San Martín, Buenos Aires, edición del autor, 1992.

Galbraith, John K., El nuevo estado industrial, Barcelona, Ariel, 1967.

Gerchunoff, Pablo y Lucas Llach, El ciclo de la ilusión y el desencanto. Un siglo de políticas económicas argentinas, Buenos Aires, Editorial Ariel, 1998.

Gerschenkron, Alexander, Economic Backwardness in Historical Perspective, a Book of Essays, Massachusetts, Belknap Press/Harvard University Press, 1962.

HARARI, IANINA, "Crónica de una privatización anunciada: alcances y límites de la producción automotriz bajo el peronismo", Anuario CEICS, Centro de Estudios e Investigaciones en Ciencias Sociales, año 1, núm. 1, 2007, Buenos Aires, pp. 47-70.

Hirschman, Albert, The Strategy of Economic Development, New Haven, Yale University Press, 1958.

Horten, Reimar y Peter Selinger, Nurflügel: Die Geschichte der Horten-Flugzeuge 19331960, Graz, H. Weishaupt Verlag, 1983.

Industrias Aeronáuticas y Mecánicas del Estado, Actas de Directorio, 1956-1957, núms. 13-52.

"Justicialistas del aire", Revista Nacional de Aeronáutica, Círculo de Aeronáutica, año XIII, núm. 138, septiembre de 1953, Buenos Aires, pp. 34-35. 
KATZ, Jorge (comp.), Del Ford Taunus a la soja transgénica. Reflexiones en torno a la transición argentina al siglo XXI, Buenos Aires, Edhasa, 2009.

y Bernardo Kosacoff, El proceso de industrialización en la Argentina: evolución, retroceso y prospectiva, Buenos Aires, Comisión Económica para América Latina y el Caribe, 1989.

Lewis, ARTHur, Economic Development with Unlimited Supplies of Labour, Manchester, Manchester School, 1954.

Lewis, Paul, La crisis del capitalismo argentino, Buenos Aires, Fondo de Cultura Económica, 1993.

MALLON, Richard y JUAN SOURROUILle, La politica económica en una sociedad conflictiva. El caso argentino, Buenos Aires, Amorrortu, 1975.

McCloud, James, The IKA Story, edición del autor, 1995.

Ministerio de AeronáuticA, Segundo Plan Quinquenal de Aeronáutica, Buenos Aires, Ministerio de Aeronáutica, 1952.

Myrdal, Gunnar, Economic Theory and Under-Developed Regions, Nueva York, Harper Torchbooks, 1957.

Odisio, JuAn, "Las capacidades del Estado empresario argentino. El desempeño de Petroquímica General Mosconi bajo gestión estatal”, Segunda Escuela de Verano de Historia Económica, Universidad de la República, Uruguay, 2011.

“Otra realidad del IAME”, Revista Nacional de Aeronáutica, Círculo de Aeronáutica, año XIII, núm. 140, noviembre de 1953, Buenos Aires.

Palmieri, Horacio y Rinaldo Colomé, "La industria manufacturera en la ciudad de Córdoba”, Desarrollo Económico, Instituto de Desarrollo Económico, vol. 5, t. 2, núms. 17-18-19, abril-diciembre de 1965, pp. 231-266.

Peña, Milcíades, Masas, caudillos y elites: la dependencia argentina de Yrigoyen a Perón, Buenos Aires, Fichas, 1971. 1986 [1964].

Industrialización y clases sociales en la Argentina, Buenos Aires, Hyspamérica,

PiCABEA, FACUNDO, "Apogeo, inercia y caída del proyecto metalmecánico tecno-nacionalista. El caso de Industrias Mecánicas del Estado (Argentina 1952-1980)", tesis de doctorado en Ciencias Sociales, Universidad de Buenos Aires, 2011.

"Por la buena senda", Revista Nacional de Aeronáutica, Círculo de Aeronáutica, año XII, núm. 122, mayo de 1952, Buenos Aires.

Prebisch, Raúl, "El desarrollo económico de la América Latina y algunos de sus principales problemas”, Santiago, Comisión Económica para América Latina y el Caribe, 1949.

Moneda sana o inflación incontenible y Plan de restablecimiento económico, Buenos Aires, Secretaría de Prensa de la Presidencia de la Nación, enero de 1956.

Presidencia de la nación, Plan de gobierno 1947-1951, Buenos Aires, Secretaría Técnica, 1946.

Acta de la declaración de la independencia económica, Buenos Aires, Presidencia de la Nación, 1947. 
Segundo Plan Quinquenal, Buenos Aires, Presidencia de la Nación, 1953.

RACCANELlo, MARIO, "La industria argentina de maquinaria agrícola, entre la economía agroexportadora y la promoción estatal”, 5tas. Jornadas de Historia Económica de la AUDHE, 2011.

RAPOPORT, MARIO, Historia económica, política y social de la Argentina (1880-2000), Buenos Aires, Ediciones Macchi, 2000.

"Rodando por las rutas de la patria”, Revista Nacional de Aeronáutica, Círculo de Aeronáutica, núm. 145, año XIV, abril de 1954, Buenos Aires.

Rosenstein-Rodan, Paul, "Problems of Industrialization of Eastern and South-Eastern Europe", The Economic Journal, Royal Economic Society, vol. 53, núms. 210211, junio-septiembre de 1943, pp. 202-211.

Rougier, Marcelo, "La política crediticia del Banco Industrial durante el primer peronismo (1944-1955)”, Documentos de Trabajo del Centro de Estudios Económicos de la Empresa y el Desarrollo, núm. 5, abril de 2001.

, "El Estado y sus empresas en el desempeño económico argentino de la segunda mitad del siglo Xx. Una revisión necesaria”, IX Congreso Internacional de la Asociación Española de Historia Económica, Murcia, 2008.

, "El empeño en producir aluminio durante el primer peronismo. Un dilema industrial de difícil resolución”, Anuario del Centro de Estudios Económicos de la Empresa y el Desarrollo, núm. 1, año 1, 2009.

, "¿Elefante o mastodonte? Reflexiones sobre el tamaño del Estado empresario en la 'edad de oro' de la industrialización por sustitución de importaciones en la Argentina” en Alberto Müller (comp.), Industria, desarrollo, historia. Ensayos en homenaje a Jorge Schvarzer, Buenos Aires, Universidad de Buenos Aires, 2009, pp. 221-257.

, "Militares, burocracia e industria. El desempeño del Complejo militarindustrial en la producción metalúrgica", Quintas Jornadas Uruguayas de Historia Económica, Montevideo, 2011.

, La economía del peronismo. Una perspectiva histórica, Buenos Aires, Sudamericana, 2012.

Schumpeter, Joseph, Capitalismo, socialismo y democracia, Buenos Aires, Claridad, 1946.

Schvarzer, Jorge, "Empresas públicas y desarrollo industrial en Argentina", Economía de América Latina, Centro de Investigación y Docencia Económicas, núm. 3, septiembre de 1979, México. , Martínez de Hoz: la lógica política de la política económica, Buenos Aires, Centro de Investigaciones Sociales sobre el Estado y la Administración, 1983.

, La industria que supimos conseguir. Una historia político-social de la industria argentina, Buenos Aires, Ediciones Cooperativas, 2000 [1996].

Secretaría de Aeronáutica, Plan Quinquenal de Aeronáutica, Buenos Aires, 1946.

"Síntesis de la doctrina peronista", Hechos e Ideas, t. 14, núm. 54, septiembre de 1948, pp. 374-384. 
Sourrouille, JuAn y Jorge LuCÁngeli, “Apuntes sobre la historia reciente de la industria argentina", Boletín Informativo Techint, núm. 219, 1980, Buenos Aires.

Thomas, Hernán, "Dinâmicas de inovação na Argentina (1970-1995). Abertura comercial, crise sistémica e rearticulação", tesis de doctorado, Campinas, Universidade Estadual de Campinas, 1999. 